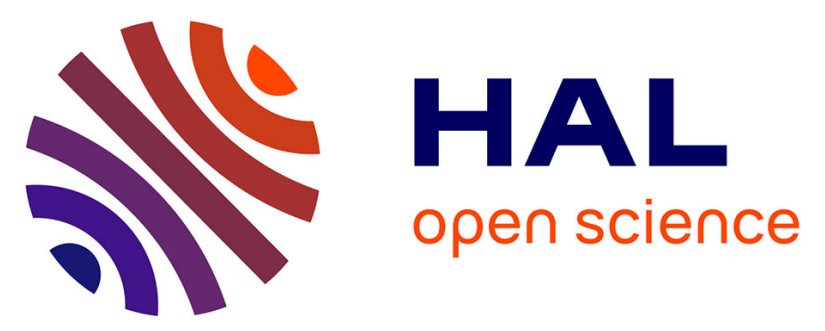

\title{
Size-resolved, real-time measurement of water-insoluble aerosols in the Chamonix and Maurienne valleys of alpine France
}

\author{
Roby Greenwald, Michael H. Bergin, Jean-Luc Jaffrezo, Gilles Aymoz, \\ Jean-Luc Besombes
}

\section{To cite this version:}

Roby Greenwald, Michael H. Bergin, Jean-Luc Jaffrezo, Gilles Aymoz, Jean-Luc Besombes. Sizeresolved, real-time measurement of water-insoluble aerosols in the Chamonix and Maurienne valleys of alpine France. Journal of Geophysical Research: Atmospheres, 2006, 111 (D09307), 1 à 18 p. 10.1029/2005JD006662 . insu-00375499

\section{HAL Id: insu-00375499 \\ https://hal-insu.archives-ouvertes.fr/insu-00375499}

Submitted on 4 Mar 2021

HAL is a multi-disciplinary open access archive for the deposit and dissemination of scientific research documents, whether they are published or not. The documents may come from teaching and research institutions in France or abroad, or from public or private research centers.
L'archive ouverte pluridisciplinaire HAL, est destinée au dépôt et à la diffusion de documents scientifiques de niveau recherche, publiés ou non, émanant des établissements d'enseignement et de recherche français ou étrangers, des laboratoires publics ou privés. 


\title{
Size-resolved, real-time measurement of water-insoluble aerosols in the Chamonix and Maurienne valleys of alpine France
}

\author{
Roby Greenwald, ${ }^{1,2}$ Michael H. Bergin, ${ }^{3}$ Jean-Luc Jaffrezo, ${ }^{4}$ Gilles Aymoz, ${ }^{4}$ \\ and Jean-Luc Besombes ${ }^{5}$ \\ Received 11 September 2005; revised 28 October 2005; accepted 16 December 2005; published 13 May 2006.
}

[1] As part of the Pollution des Vallées Alpines (PoVA) program, the number concentration and size distribution of the total $\mathrm{PM}_{2.5}$ population, as well as the subset that is water-insoluble, were measured in the Chamonix and Maurienne Valleys of the French Alps. This program included both summer and winter intensive campaigns in January and June-July 2003. The water-insoluble aerosol (WIA) measurements were performed using a new real-time technique developed at the Georgia Institute of Technology. The concentration of both the total aerosol population and WIA was found to be highly variable on timescales as brief as a few minutes and was generally much higher in winter than in summer. In addition, the fraction (by number) of aerosols which are not soluble in water was also found to be variable and slightly higher in winter. The average insoluble fraction in the size range of $0.25-2.0 \mu \mathrm{m}$ was approximately $11 \%$ in Chamonix in both winter and summer. In the Maurienne Valley the insoluble fraction was $10 \%$ in winter and $8 \%$ in summer. Although the number concentration of WIA is dominated by particles smaller than $0.35 \mu \mathrm{m}$, a peak is consistently observed between 0.4 and $0.5 \mu \mathrm{m}$. Size-resolved filter samples were also collected as part of the PoVA program and were analyzed for EC/OC mass. Comparison of these two data sets suggests that WIA in these valleys is dominated by elemental carbon emissions from motor vehicle traffic, although mineral aerosols also contribute during the summer season. Further analysis also suggests that water-soluble and water-insoluble aerosols have sources which are independent of one another both temporally and spatially.

Citation: Greenwald, R., M. H. Bergin, J.-L. Jaffrezo, G. Aymoz, and J.-L. Besombes (2006), Size-resolved, real-time measurement of water-insoluble aerosols in the Chamonix and Maurienne valleys of alpine France, J. Geophys. Res., 111, D09307, doi:10.1029/2005JD006662.

\section{Introduction}

[2] Because of their influence on climate and health, it is important to characterize the size distribution and concentration of water-insoluble aerosols (WIA) at many different locations around the world at various times of year and under a range of meteorological conditions. Since the interaction of insoluble particles with atmospheric water vapor is quite different than that of soluble particles [Saxena

\footnotetext{
${ }^{1}$ School of Civil and Environmental Engineering, Georgia Institute of Technology, Atlanta, Georgia, USA.

${ }^{2}$ Now at Department of Pediatrics, Emory University School of Medicine, Atlanta, Georgia, USA.

${ }^{3}$ School of Civil and Environmental Engineering, School of Earth and Atmospheric Sciences, Georgia Institute of Technology, Atlanta, Georgia, USA.

${ }^{4}$ Laboratoire de Glaciologie et Géophysique de l'Environnement (LGGE), Université de Joseph Fourier, Saint Martin d'Hères, France.

${ }^{5}$ Laboratoire de Chimie Moléculaire et Environnement (LCME), Université de Savoie, Le Bourget du Lac, France.

Copyright 2006 by the American Geophysical Union. 0148-0227/06/2005JD006662
}

et al., 1995], it is important for climate modelers to possess information concerning the relative prevalence of WIA and their size distribution. WIAs exhibit less hygroscopic growth in the presence of water vapor than soluble particles and are also less likely to activate to form a cloud droplet [Hanel, 1976; Laakonsen et al., 1998]. Both of these properties imply that the influence of WIA on the radiation budget of the planet is different than that of soluble species. Inhalation of fine particulate matter is known to have a deleterious effect on human health [Peel et al., 2005; Brook et al., 2002; Peters et al., 2001, and others]. Elemental carbon in the form of soot has been observed to have specific properties harmful to lung tissue [Sosnowski et al., 2000] and to be highly correlated with cardiovascular problems [Metzger et al., 2004; Le Tertre et al., 2002]. Despite the relevance of these properties, very few ambient measurements of WIA concentration have been published in the literature, primarily due to a lack of appropriate instrumentation. A new technique to measure the size-resolved number concentration of WIA in near real time has been developed at the Georgia Institute of Technology and is described in detail by Greenwald et al. [2005]. This instrumentation for the first time provides a relatively easy 
method to measure in real time the ambient concentration of WIA at remote locations around the world.

[3] The first full-scale field use of this new technique was in conjunction with the Pollution des Vallées Alpines (PoVA) program in the French Alps in 2003. This program was established to assess the influence on local air quality of vehicular traffic on the region's main transnational highways. Sampling sites were established in the Chamonix Valley near the Mont Blanc tunnel and in the Maurienne Valley near the Fréjus tunnel. The WIA sampling system was implemented during both winter and summer intensive sampling campaigns in January and June-July 2003.

[4] In addition to demonstrating the field performance of the insoluble aerosol measurement system, this paper is intended to provide detailed information concerning the size distribution and concentration of WIA in these valleys and to describe the temporal variability of these values on both a long- and short-term scale. By comparing the data retrieved from the WIA sampling apparatus with that gathered by other components of the PoVA program, it is also possible to examine possible sources for WIA, to infer some information concerning the chemical speciation of WIA, and to observe the behavior of WIA under the influence of various atmospheric processes such as precipitation events and changes in solar insolation and atmospheric humidity.

\section{Experimental Approach}

\subsection{Instrumentation}

[5] The number size distribution and concentration of WIA were measured using a newly developed real-time technique. This system uses an SKC Biosampler impinger to entrain particles into a circulating water stream. Filtered, ultrapure water is pumped into the impinger chamber where it is mixed with ambient air. The impinger has a high collection efficiency $(>80 \%)$ at all measured particle sizes. The liquid outflow from the impinger is sent through a passive debubbling device and then through a Particle Measuring Systems LiQuilaz SO2 optical particle counter. The concentration of WIA in the air may be calculated from the measured concentration in the liquid by the following equation:

$$
C_{a i r, i}=C_{l, i} \frac{Q_{l}}{Q_{a i r}}
$$

where $C_{a i r, i}$ is the concentration of particles of size $i$ in the air, $C_{l, i}$ is the concentration of particles of size $i$ in the liquid, $Q_{\text {air }}$ is the flow rate of ambient air, and $Q_{l}$ is the liquid flow rate.

[6] The LiQuilaz SO2 uses a $780 \mathrm{~nm}$ wavelength laser and detects light scattering from $9^{\circ}-45^{\circ}$ relative to the forward direction of the light source. This instrument uses a liquid medium for light scattering which in the case of this study was water. The refractive index of water is $1.33+$ $0.0 i$, so consequently, only particles with a refractive index significantly different from this value are detectable by the LiQuilaz. This instrument measures the particle size distribution in fifteen size channels ranging from 0.25 to $2.0 \mu \mathrm{m}$ based on a calibration using polystyrene latex (PSL) spheres of various known diameters.
[7] The size-resolved total concentration of particles in the air was measured simultaneously using a GRIMM dust monitor model 1.100. This model of optical particle counter sizes aerosols in seven channels between 0.3 and $2.0 \mu \mathrm{m}$ and eight channels between 2.0 and $20 \mu \mathrm{m}$. By comparing the concentration of WIA in the air derived from equation (1) to the total concentration measured by the GRIMM dust monitor, the real-time fraction of particles which are waterinsoluble may be calculated on a size-resolved basis. For this study, the time resolution used was $5 \mathrm{~min}$. The waterinsoluble instrumentation was installed inside a portable wooden shelter about $2 \mathrm{~m}^{3}$ in volume. The ambient air inlet was located approximately $2 \mathrm{~m}$ above the ground. The GRIMM dust monitor was installed on the top of this shelter.

[8] Filter samples were also collected and analyzed for elemental and organic carbon (EC/OC) mass using the thermal/optical transmittance (TOT) method developed by Sunset Laboratory [Birch and Cary, 1996]. This technique is subject to two sources of uncertainty: error in determining the distinction between EC and $\mathrm{OC}$ as well as positive $\mathrm{OC}$ artifacts due to adsorption of gas-phase organics [Turpin et al., 2000]. The uncertainty in the EC/OC split point does not influence the total amount of carbon detected such that shifting the split toward higher OC mass results in correspondingly less EC mass and vice versa; however, the uncertainty in EC mass due to an inaccurate split point may be either positive or negative and depends on particle composition [Yang and $Y u, 2002]$. The uncertainty due to positive OC artifacts from adsorbed gas-phase species may be significant and as high as $20-30 \%$. The reported mass inferred from TOT analysis is the mass of carbon alone and does not include the mass of other elements present in the particle. In the case of EC, carbon mass and particle mass are very close, but in the case of OC, particle mass may be 1.4-2.1 times higher than carbon mass [Turpin et al., 2000]. Two different filtering systems were used for TOT analysis: total $\mathrm{PM}_{2.5}$ mass was collected on quartz filters over a period of four hours and size resolved EC/OC mass was collected over a period of 24 hours using a Dekati low pressure cascade impactor. These results are discussed in more detail by Jaffrezo et al. [2005a]. Another set of sizeresolved filter measurements were made on Teflon filters over a period of 48 hours using a MOUDI cascade impactor in order to gravimetrically determine total particle mass.

\subsection{Discussion of Measurement Uncertainty \\ 2.2.1. Instrumental Uncertainty}

[9] As has been observed since the earliest uses of optical particle counters, instruments which rely on aerosol light scattering to measure particle size and concentration inherently depend on assumptions of particle shape and refractive index [Quenzel, 1969; Whitby and Vomela, 1967]. Uncertainty in the size of detected particles arises from the fact that many ambient insoluble particles are nonspherical and have a refractive index significantly different from that of the most common calibration standard, polystyrene latex (PSL). The refractive index of this material is $1.59+0.0 i$ at $\lambda=780 \mathrm{~nm}$. Estimates of the refractive index of black carbon chain agglomerates range from $1.1+0.1 i$ for agglomerates with an open structure and many air spaces to $1.5+0.5 i$ for more densely packed agglomerates (Hull et 
Table 1. Mean Values, Ranges, Standard Deviations, and Standard Errors of the Mean for All Measured Aerosol Quantities

\begin{tabular}{|c|c|c|c|c|c|c|c|c|}
\hline $\begin{array}{l}\text { Sampling } \\
\text { Location }\end{array}$ & $\begin{array}{l}\text { Sampling } \\
\text { Season }^{\mathrm{a}}\end{array}$ & $\begin{array}{l}\text { Measured } \\
\text { Quantity }\end{array}$ & Mean & Minimum & Maximum & $\begin{array}{c}\text { Standard } \\
\text { Deviation }\end{array}$ & $\begin{array}{l}\text { Standard } \\
\text { Error of the } \\
\text { Mean }\end{array}$ & $\mathrm{N}^{\mathrm{b}}$ \\
\hline Chamonix & winter & $\begin{array}{l}\text { total number } \\
\text { concentration }^{\mathrm{c}}\end{array}$ & $148 \mathrm{~cm}^{-3}$ & $12 \mathrm{~cm}^{-3}$ & $1079 \mathrm{~cm}^{-3}$ & $144 \mathrm{~cm}^{-3}$ & $4.6 \mathrm{~cm}^{-3}$ & 982 \\
\hline Chamonix & winter & $\begin{array}{l}\text { WIA number } \\
\text { concentration }^{\mathrm{c}}\end{array}$ & $12.1 \mathrm{~cm}^{-3}$ & $1.1 \mathrm{~cm}^{-3}$ & $49 \mathrm{~cm}^{-3}$ & $9.0 \mathrm{~cm}^{-3}$ & $0.3 \mathrm{~cm}^{-3}$ & 915 \\
\hline Chamonix & winter & $\begin{array}{l}\text { number insoluble } \\
\text { fraction }^{\mathrm{c}}\end{array}$ & 0.11 & 0.014 & 0.69 & 0.085 & 0.003 & 907 \\
\hline Chamonix & winter & $\begin{array}{l}\mathrm{PM}_{2.5} \text { EC mass } \\
\text { concentration }\end{array}$ & $3.4 \mu \mathrm{g} \times \mathrm{m}^{-3}$ & $0.77 \mu \mathrm{g} \times \mathrm{m}^{-3}$ & $11 \mu \mathrm{g} \times \mathrm{m}^{-3}$ & $2.9 \mu \mathrm{g} \times \mathrm{m}^{-3}$ & $0.79 \mu \mathrm{g} \times \mathrm{m}^{-3}$ & 13 \\
\hline Chamonix & winter & $\begin{array}{r}\mathrm{PM}_{2.5} \mathrm{OC} \text { mass } \\
\text { concentration }\end{array}$ & $9.4 \mu \mathrm{g} \times \mathrm{m}^{-3}$ & $3.5 \mu \mathrm{g} \times \mathrm{m}^{-3}$ & $20 \mu \mathrm{g} \times \mathrm{m}^{-3}$ & $4.5 \mu \mathrm{g} \times \mathrm{m}^{-3}$ & $1.2 \mu \mathrm{g} \times \mathrm{m}^{-3}$ & 13 \\
\hline Chamonix & winter & $\begin{array}{l}\mathrm{PM}_{3} \text { mass } \\
\text { concentration }^{\mathrm{d}}\end{array}$ & $17 \mu \mathrm{g} \times \mathrm{m}^{-3}$ & $11 \mu \mathrm{g} \times \mathrm{m}^{-3}$ & $23 \mu \mathrm{g} \times \mathrm{m}^{-3}$ & $9.1 \mu \mathrm{g} \times \mathrm{m}^{-3}$ & $6.4 \mu \mathrm{g} \times \mathrm{m}^{-3}$ & 2 \\
\hline Maurienne & winter & $\begin{array}{l}\text { total number } \\
\text { concentration }^{\mathrm{c}}\end{array}$ & $69 \mathrm{~cm}^{-3}$ & $3.3 \mathrm{~cm}^{-3}$ & $317 \mathrm{~cm}^{-3}$ & $46 \mathrm{~cm}^{-3}$ & $1.1 \mathrm{~cm}^{-3}$ & 1848 \\
\hline Maurienne & winter & $\begin{array}{l}\text { WIA number } \\
\text { concentration }^{\mathrm{c}}\end{array}$ & $5.3 \mathrm{~cm}^{-3}$ & $0.55 \mathrm{~cm}^{-3}$ & $20 \mathrm{~cm}^{-3}$ & $3.4 \mathrm{~cm}^{-3}$ & $0.08 \mathrm{~cm}^{-3}$ & 1937 \\
\hline Maurienne & winter & $\begin{array}{l}\text { number insoluble } \\
\text { fraction }^{\mathrm{c}}\end{array}$ & 0.096 & 0.014 & 0.60 & 0.057 & 0.001 & 1796 \\
\hline Maurienne & winter & $\begin{array}{r}\mathrm{PM}_{2.5} \text { EC mass } \\
\text { concentration }\end{array}$ & $0.57 \mu \mathrm{g} \times \mathrm{m}^{-3}$ & $0.11 \mu \mathrm{g} \times \mathrm{m}^{-3}$ & $5.9 \mu \mathrm{g} \times \mathrm{m}^{-3}$ & $0.37 \mu \mathrm{g} \times \mathrm{m}^{-3}$ & $0.074 \mu \mathrm{g} \times \mathrm{m}^{-3}$ & 25 \\
\hline Maurienne & winter & $\begin{array}{r}\mathrm{PM}_{2.5} \mathrm{OC} \text { mass } \\
\text { concentration }\end{array}$ & $1.7 \mu \mathrm{g} \times \mathrm{m}^{-3}$ & $0.20 \mu \mathrm{g} \times \mathrm{m}^{-3}$ & $4.2 \mu \mathrm{g} \times \mathrm{m}^{-3}$ & $1.1 \mu \mathrm{g} \times \mathrm{m}^{-3}$ & $0.21 \mu \mathrm{g} \times \mathrm{m}^{-3}$ & 25 \\
\hline Maurienne & winter & $\begin{array}{l}\mathrm{PM}_{3} \text { mass } \\
\text { concentration }^{\mathrm{d}}\end{array}$ & $7.8 \mu \mathrm{g} \times \mathrm{m}^{-3}$ & - & - & - & - & 1 \\
\hline Chamonix & summer & $\begin{array}{l}\text { total number } \\
\text { concentration }^{\mathrm{c}}\end{array}$ & $72 \mathrm{~cm}^{-3}$ & $10 \mathrm{~cm}^{-3}$ & $311 \mathrm{~cm}^{-3}$ & $42 \mathrm{~cm}^{-3}$ & $0.95 \mathrm{~cm}^{-3}$ & 1969 \\
\hline Chamonix & summer & $\begin{array}{l}\text { WIA number } \\
\text { concentration }^{\mathrm{c}}\end{array}$ & $6.7 \mathrm{~cm}^{-3}$ & $0.99 \mathrm{~cm}^{-3}$ & $62 \mathrm{~cm}^{-3}$ & $4.2 \mathrm{~cm}^{-3}$ & $0.10 \mathrm{~cm}^{-3}$ & 1788 \\
\hline Chamonix & summer & $\begin{array}{l}\text { number insoluble } \\
\text { fraction }^{\mathrm{c}}\end{array}$ & 0.11 & 0.023 & 0.90 & 0.064 & 0.002 & 1771 \\
\hline Chamonix & summer & $\begin{array}{r}\mathrm{PM}_{2.5} \text { EC mass } \\
\text { concentration }\end{array}$ & $1.2 \mu \mathrm{g} \times \mathrm{m}^{-3}$ & $0.48 \mu \mathrm{g} \times \mathrm{m}^{-3}$ & $11 \mu \mathrm{g} \times \mathrm{m}^{-3}$ & $1.9 \mu \mathrm{g} \times \mathrm{m}^{-3}$ & $0.36 \mu \mathrm{g} \times \mathrm{m}^{-3}$ & 29 \\
\hline Chamonix & summer & $\begin{array}{r}\mathrm{PM}_{2.5} \text { OC mass } \\
\text { concentration }\end{array}$ & $6.6 \mu \mathrm{g} \times \mathrm{m}^{-3}$ & $3.8 \mu \mathrm{g} \times \mathrm{m}^{-3}$ & $9.8 \mu \mathrm{g} \times \mathrm{m}^{-3}$ & $1.7 \mu \mathrm{g} \times \mathrm{m}^{-3}$ & $0.32 \mu \mathrm{g} \times \mathrm{m}^{-3}$ & 29 \\
\hline Chamonix & summer & $\begin{array}{l}\mathrm{PM}_{3} \text { mass } \\
\text { concentration }^{\mathrm{d}}\end{array}$ & $8.3 \mu \mathrm{g} \times \mathrm{m}^{-3}$ & $4.7 \mu \mathrm{g} \times \mathrm{m}^{-3}$ & $11 \mu \mathrm{g} \times \mathrm{m}^{-3}$ & $3.1 \mu \mathrm{g} \times \mathrm{m}^{-3}$ & $1.6 \mu \mathrm{g} \times \mathrm{m}^{-3}$ & 4 \\
\hline Maurienne & summer & $\begin{array}{l}\text { total number } \\
\text { concentration }^{\mathrm{c}}\end{array}$ & $71 \mathrm{~cm}^{-3}$ & $32 \mathrm{~cm}^{-3}$ & $111 \mathrm{~cm}^{-3}$ & $21 \mathrm{~cm}^{-3}$ & $0.91 \mathrm{~cm}^{-3}$ & 539 \\
\hline Maurienne & summer & $\begin{array}{l}\text { WIA number } \\
\text { concentration }^{\mathrm{c}}\end{array}$ & $5.8 \mathrm{~cm}^{-3}$ & $0.19 \mathrm{~cm}^{-3}$ & $38 \mathrm{~cm}^{-3}$ & $2.1 \mathrm{~cm}^{-3}$ & $0.074 \mathrm{~cm}^{-3}$ & 814 \\
\hline Maurienne & summer & $\begin{array}{l}\text { number insoluble } \\
\text { fraction }^{\mathrm{c}}\end{array}$ & 0.082 & 0.040 & 0.66 & 0.041 & 0.002 & 529 \\
\hline Maurienne & summer & $\begin{array}{l}\mathrm{PM}_{2.5} \text { EC mass } \\
\text { concentration }\end{array}$ & $0.55 \mu \mathrm{g} \times \mathrm{m}^{-3}$ & $0.32 \mu \mathrm{g} \times \mathrm{m}^{-3}$ & $0.80 \mu \mathrm{g} \times \mathrm{m}^{-3}$ & $0.15 \mu \mathrm{g} \times \mathrm{m}^{-3}$ & $0.040 \mu \mathrm{g} \times \mathrm{m}^{-3}$ & 15 \\
\hline Maurienne & summer & $\begin{array}{r}\mathrm{PM}_{2.5} \mathrm{OC} \text { mass } \\
\text { concentration }\end{array}$ & $6.4 \mu \mathrm{g} \times \mathrm{m}^{-3}$ & $3.2 \mu \mathrm{g} \times \mathrm{m}^{-3}$ & $9.4 \mu \mathrm{g} \times \mathrm{m}^{-3}$ & $2.1 \mu \mathrm{g} \times \mathrm{m}^{-3}$ & $0.54 \mu \mathrm{g} \times \mathrm{m}^{-3}$ & 15 \\
\hline Maurienne & summer & $\begin{array}{l}\mathrm{PM}_{3} \text { mass } \\
\text { concentration }^{\mathrm{d}}\end{array}$ & $8.9 \mu \mathrm{g} \times \mathrm{m}^{-3}$ & $8.1 \mu \mathrm{g} \times \mathrm{m}^{-3}$ & $9.6 \mu \mathrm{g} \times \mathrm{m}^{-3}$ & $1.0 \mu \mathrm{g} \times \mathrm{m}^{-3}$ & $0.74 \mu \mathrm{g} \times \mathrm{m}^{-3}$ & 2 \\
\hline
\end{tabular}

${ }^{a}$ The sampling period in the Chamonix Valley was 18-22 January 2003 and 4-11 July 2003. The sampling period in the Maurienne Valley was 2430 January 2003 and 25 June to 2 July 2003.

${ }^{\mathrm{b}}$ Number of data points.

${ }^{c}$ In the size range $\mathrm{D}_{\mathrm{p}}=0.3-2.0 \mu \mathrm{m}$.

${ }^{\mathrm{d}}$ Sum of MOUDI stages with nominal cut size $<3.1 \mu \mathrm{m}$.

al. [2004]; see Greenwald et al. [2005] for more thorough analysis). Mineral aerosols generally have a real refractive index of 1.5-1.6 with a minimal absorptive component in the visible and near-visible range [Sokolik and Toon, 1999]. The composition of organic aerosols is quite complex and largely unknown, although the refractive indices of individual organic compounds known to be water-insoluble are generally 1.4-1.5 [Lide, 2004].

[10] Mie theory analysis of this instrument to estimate the influence of particle refractive index has suggested that the LiQuilaz is accurate within $\pm 20-30 \%$ for particles smaller than $0.6 \mu \mathrm{m}$. For particles greater than $0.6 \mu \mathrm{m}$, the resulting uncertainty in inferred particle size is nearly always negative (i.e., particles are undersized) and of somewhat greater magnitude (as much as 50\%). As discussed in the work of Greenwald et al. [2005], it is highly unlikely that particles reported by the LiQuilaz to be larger than $0.8 \mu \mathrm{m}$ may be composed of black carbon (BC). This does not imply that such large BC particles are not detected, but rather that they are undersized by the LiQuilaz on the order of $40-80 \%$. Particles which are indicated to be greater than $0.8 \mu \mathrm{m}$ must therefore be composed of some different insoluble material. 


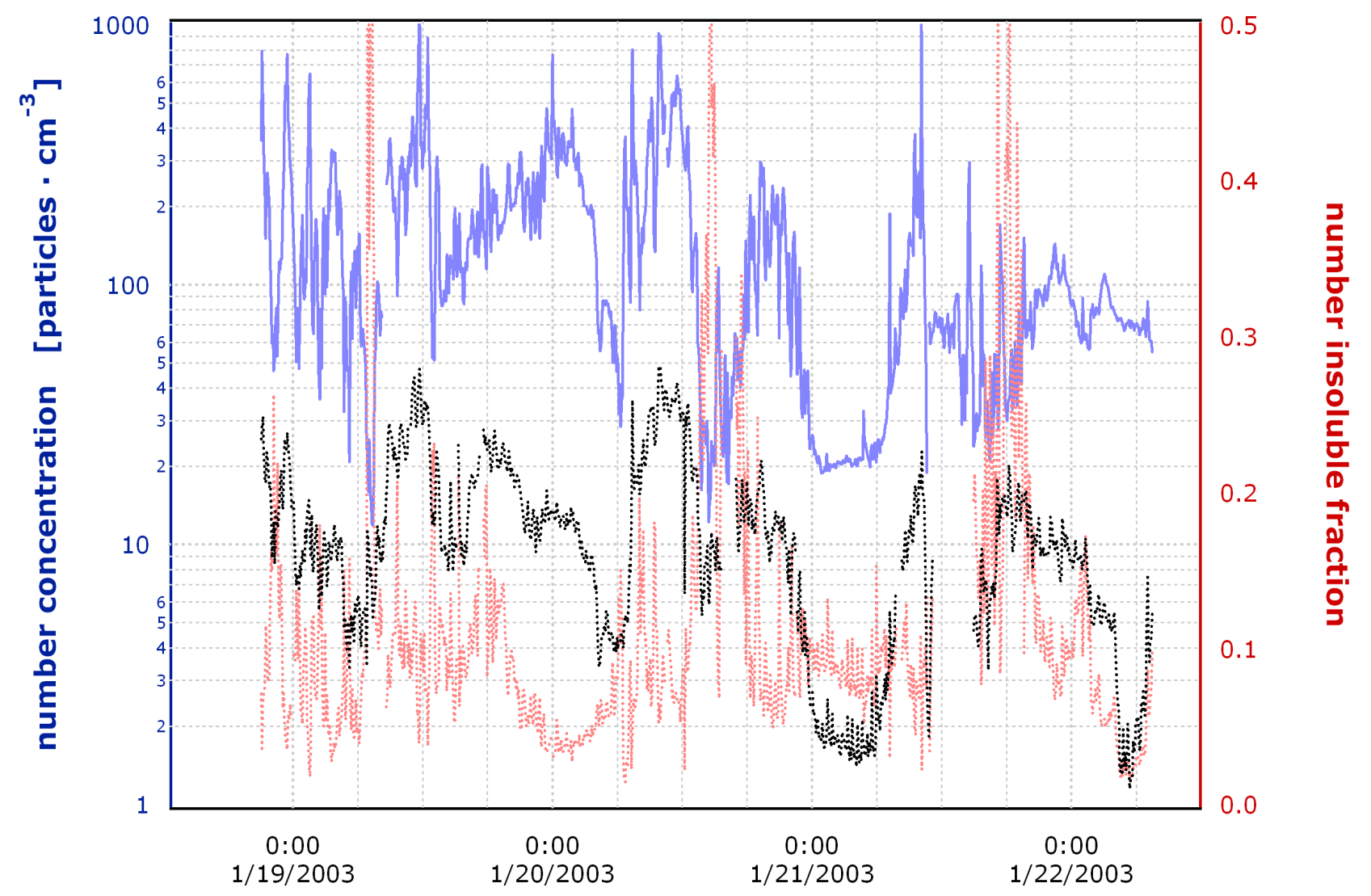

Figure 1. Time series of the total aerosol and WIA number concentration in the Chamonix Valley during the winter 2003 campaign. Displayed data show the sum of all particles in the size range $0.3-2.0 \mu \mathrm{m}$. Total aerosol, solid blue line; WIA, dotted black line; number insoluble fraction, dotted red line.

Since the size distribution of mineral aerosols tends to be shifted toward larger sizes relative to that of organic aerosols [Ebert et al., 2004], these particles are more likely to be of crustal origin.

[11] In the case of internally mixed aerosols, particle refractive index is also influenced by the presence of extraneous material. Agglomerates of black carbon typically contain some quantity of organic compounds, and well-aged soot particles are often coated by a substantial amount of organic and inorganic matter [Pósfai et al., 1999]. Inorganic matter such as sulfate and a substantial portion of the organic matter is likely to be water-soluble and therefore dissolve before reaching the LiQuilaz used in this study. The real-time technique to measure WIA number concentration used for this study is not able to provide information on the mixing state of particles or quantify the amount of soluble material present on a particle in its atmospheric state. Insoluble particles reported to be a specific size by this technique may have existed in the atmosphere as a larger internally mixed particle containing both soluble and insoluble mass. Similarly, mostly soluble particles with only a small insoluble core or soot agglomerates which disaggregate may not be detected at all if the remaining fragments are smaller than $0.25 \mu \mathrm{m}$. On the other hand, provided that the illuminated surface of a particle is of sufficient size and refractive index to scatter a quantity of light greater than the sensitivity of the photodetectors, the measured number concentration is generally considered to be accurate at concentrations up to the coincidence limit. The LiQuilaz's coincidence limit is 10,000 particles per $\mathrm{mL}$, and ambient particle concentrations were below this limit at all times during this study.

[12] The impinger device used by this instrument to entrain atmospheric particles into a liquid stream may be an additional source of uncertainty. The collection efficiency of this device is a function of particle size and is close to $100 \%$ for particles larger than $1.0 \mu \mathrm{m}$, is $90 \%$ for $0.5 \mu \mathrm{m}$ particles and is $80 \%$ for $0.3 \mu \mathrm{m}$ particles. In the important size range of $0.3-0.5 \mu \mathrm{m}, 10-20 \%$ of the ambient particles will not be entrained into the liquid sample.

[13] Measurements of the fraction of organic aerosol mass which is water-soluble at the same alpine sites as examined in this study have found a seasonal pattern with $55 \pm 8 \%$ of the organic mass being water-soluble in the winter and $76 \pm$ $6 \%$ in the summer [Jaffrezo et al., 2005b]. The real-time technique is less efficient at measuring water-insoluble organic carbon than other types of insoluble aerosols. This is likely due to the combined effect of three properties of organic aerosols. First, the refractive index of insoluble organic compounds is frequently similar to that of the scattering medium of the particle counter. Many insoluble organic compounds therefore do not scatter enough light to 

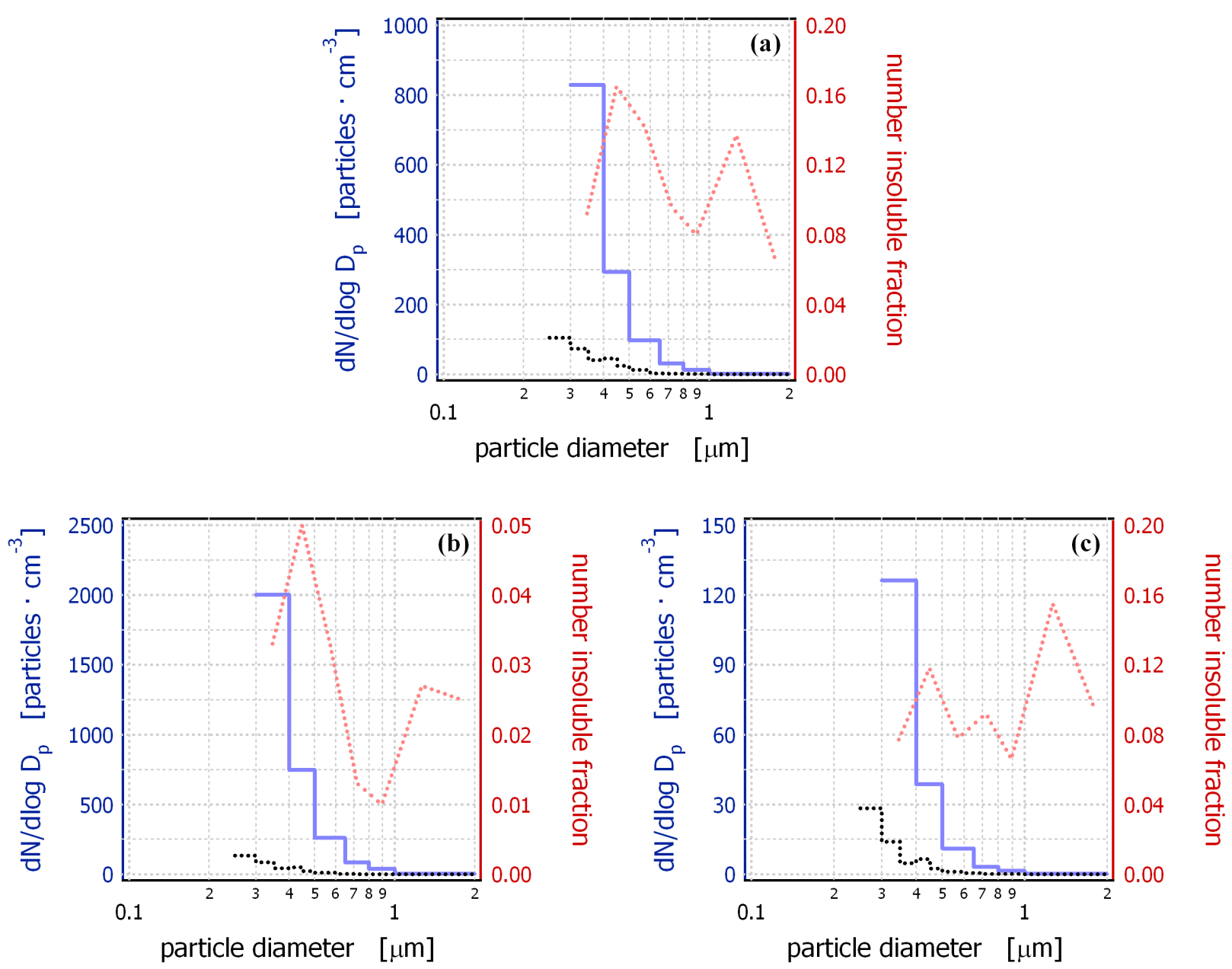

Figure 2. Number size distribution of the total aerosol and WIA number concentration in the Chamonix Valley during the winter 2003 campaign. Figure $2 \mathrm{a}$ is averaged over the entire sampling period, Figure $2 \mathrm{~b}$ shows the period around midnight on 20 January, when concentrations were elevated for several hours, and Figure $2 \mathrm{c}$ is the period during the morning of 21 January, when the concentration was low for several hours. Total aerosol, solid blue line; WIA, dotted black line; number insoluble fraction, dotted red line.
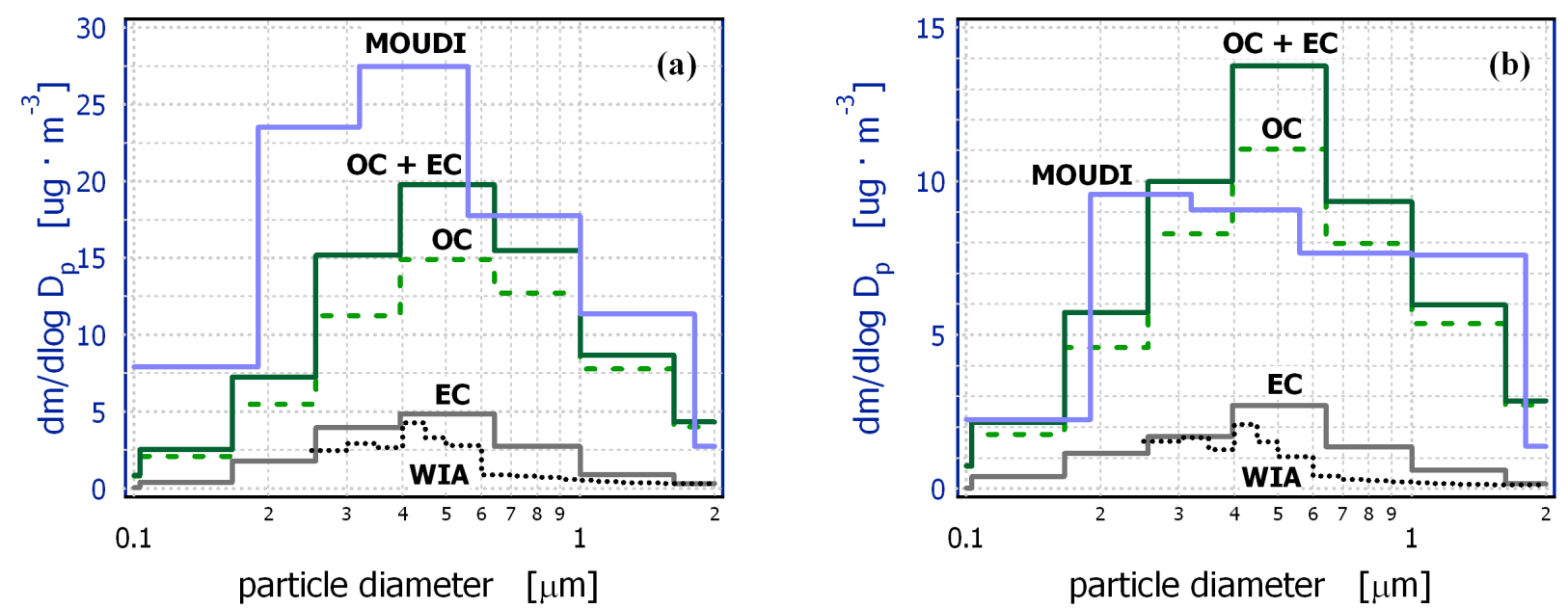

Figure 3. Mass size distributions in the Chamonix Valley during the winter 2003 campaign. Total mass was measured gravimetrically using a MOUDI cascade impactor, and carbonaceous mass was measured by TOT analysis of Dekati cascade impactor samples. Figure 3a is for the time period of 18-20 January 2003, and Figure 3b is for 20-22 January 2003. 


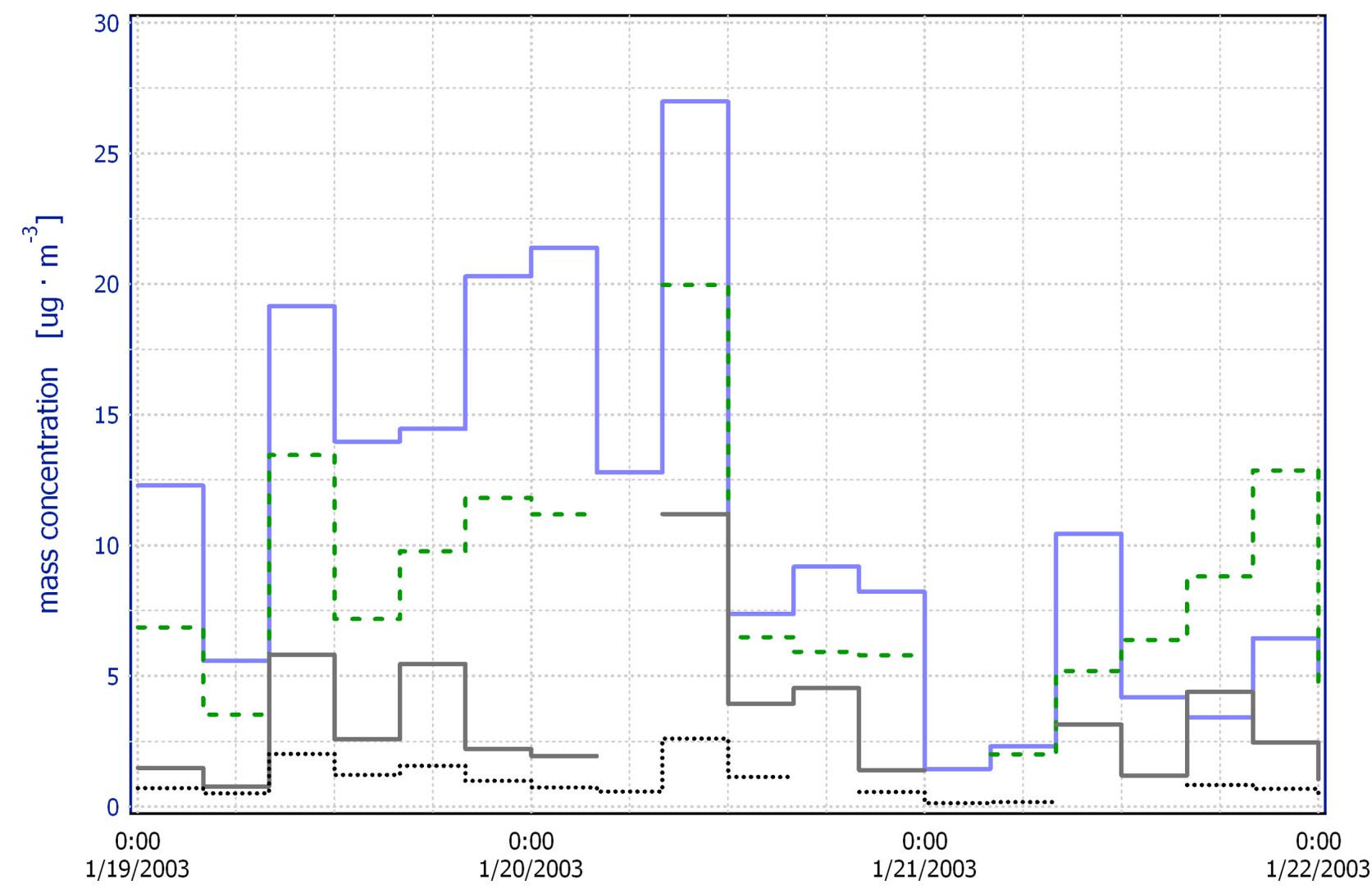

Figure 4. Time series of the elemental and organic carbon mass concentration in the Chamonix Valley during the winter 2003 campaign. The data were obtained from TOT analysis of $\mathrm{PM}_{2.5}$ filters sampled on 4-hour intervals. Estimates of the total aerosol and WIA mass concentration calculated from the measured number concentration in the size range $0.3-2.0 \mu \mathrm{m}$ are also shown. Total aerosol, solid blue line; WIA, dotted black line; OC mass, dashed green line; EC mass, solid gray line.

be detected by the LiQuilaz. Organics which are detected by the particle counter are likely to be undersized to a greater extent than other types of insoluble particles. The net result is an undercounting of insoluble organic aerosols. In addition, since the environment inside of the impinging chamber is nearly infinitely dilute, particles determined to be insoluble by filter-based analysis techniques may in fact be partially soluble in our system.

\subsubsection{Comparison of Data Sets}

[14] The process of sizing of elemental carbon particles with a cascade impactor and TOT filter analysis results in a particle diameter which is not perfectly analogous to the size reported by the LiQuilaz even in the absence of the previously mentioned uncertainty. Cascade impactors segregate particles based on inertia. Particle inertia is a function of mass, shape and velocity. Internally mixed particles are sized based on the combined mass of all species; however, it is known that well-aged soot particles tend to contain a significant coating of water-soluble organic or ionic compounds [Pósfai et al., 1999]. This coating material will dissolve in the water stream sampled by the LiQuilaz, resulting in a diameter smaller than that suggested by impactor filter analysis for EC particles. In addition, filter samples provide a measurement of mass concentration, whereas particle counters report a number concentration.
Data conversion between the two concentrations is not a straightforward process since particle density and shape is unknown and particularly in the case of soot particles, highly variable. For purposes of comparison of the data sets, an approximation of WIA mass was calculated from the number concentrations by assuming that particles are spherical with a diameter equal to the log average of the corresponding instrument channel and have a density of $1.7 \mathrm{~g} \times \mathrm{cm}^{-3}$ (typical for ionic aerosols) for the total population and $1.8 \mathrm{~g} \times \mathrm{cm}^{-3}$ (representative of elemental carbon) for WIA [Janzen, 1980]. Since volume is a function of diameter cubed, small inaccuracies in the measurement of diameter can result in large inaccuracies in the estimate of mass. In addition, the density of soot is also uncertain and likely varies as a function of size. The bulk density of black carbon has been estimated to be approximately $2 \mathrm{~g} \times \mathrm{cm}^{-3}$ [Hess and Herd, 1993]. This value represents the maximum possible density of an individual soot particle; as porosity increases, particle density decreases correspondingly. Since these filter measurements have poor time resolution (448 hours versus $5 \mathrm{~min}$ ), use a different method to size particles (inertia versus light scattering), and measure mass instead of number, comparison of the resulting data with the real-time WIA measurements should be interpreted qualitatively instead of quantitatively. 

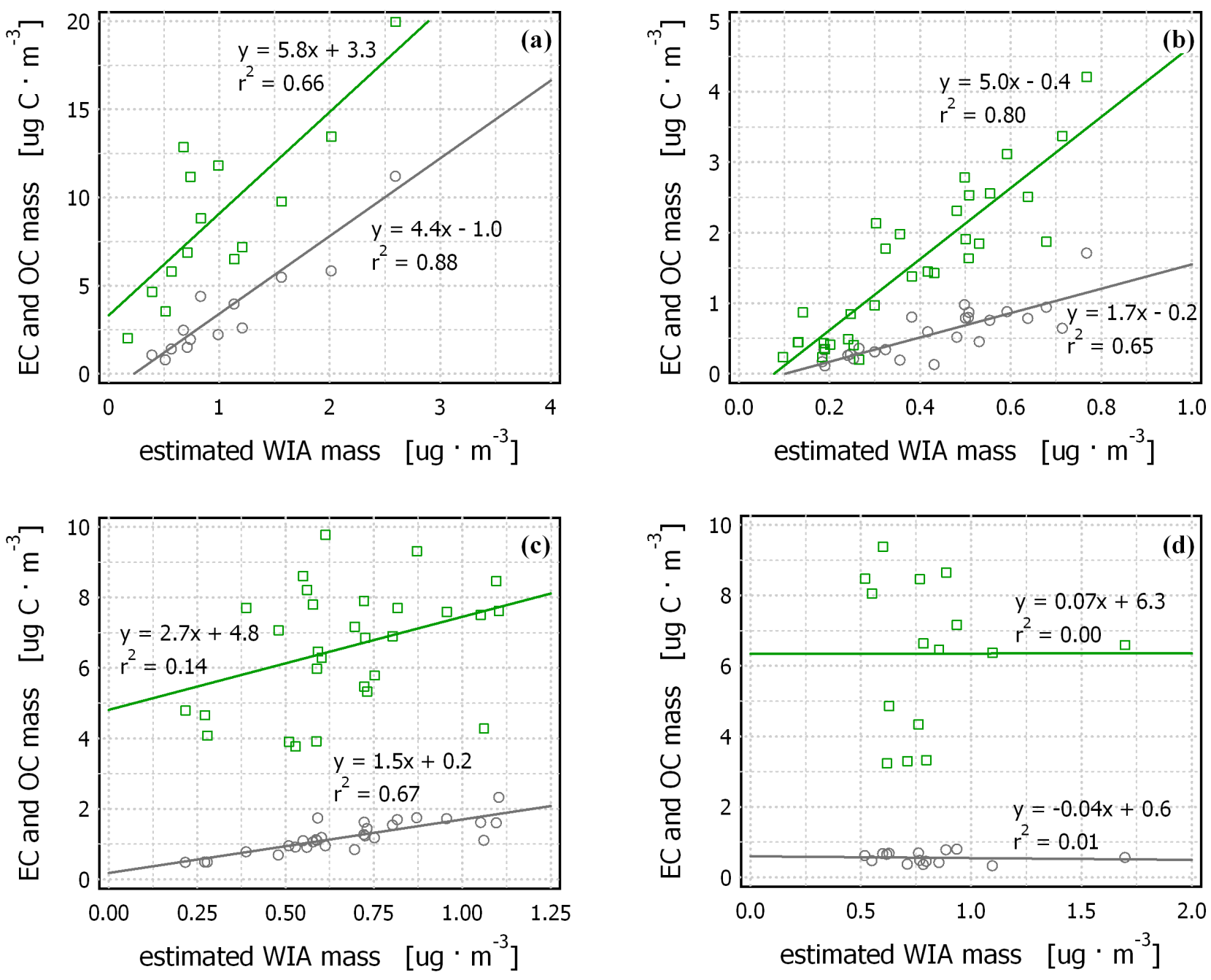

Figure 5. Linear regressions of measured EC and OC mass with the estimated WIA mass concentration. Figure $5 \mathrm{a}$ is for Chamonix winter, Figure $5 \mathrm{~b}$ is for Maurienne winter, Figure $5 \mathrm{c}$ is for Chamonix summer, and Figure 5d is for Maurienne summer. EC, gray circles; OC, green squares.

\subsection{Sampling Sites}

[15] Sampling sites for the intensive field campaigns were chosen at representative locations in both the Chamonix and Maurienne Valleys. The Chamonix Valley is a $23 \mathrm{~km}$ long valley on the borders of France, Italy, and Switzerland. The mean elevation of the valley floor is $1000 \mathrm{~m}$ above sea level. It is $1-2 \mathrm{~km}$ wide on average and is bounded by very steep mountain slopes, the tallest of which is Mont Blanc at $4807 \mathrm{~m}$. There are 12,000 permanent residents in the valley, but this number is exceeded by the tourist population of roughly 5 million overnight visits per year. There are no major industrial installations in this valley, although it does contain a major highway which passes through the Mont Blanc tunnel to Italy. During the winter campaign, the traffic on this highway was comprised of approximately 1800 personal vehicles and 600 heavy trucks per day. During the summer campaign, these numbers had increased to 4200 personal vehicles and 900 trucks per day. Approximately half of the personal vehicles are diesel powered. The valley also contains a much smaller road traversing the length of the valley through the high mountain pass leading to
Switzerland (the Col des Montets). This road carries much less traffic, largely personal vehicles driven by tourists. There are also many secondary roads leading only to small villages and neighborhoods near the floor of the valley. In Chamonix, the instrumentation was set up in the backyard of a chalet owned by LGGE in a residential area known as Le Clos de l'Ours, about $1 \mathrm{~km}$ from the center of the town of Chamonix and near the valley floor. This site is located $2 \mathrm{~km}$ up the valley from the entrance to the Mont Blanc tunnel. The sampling period in Chamonix was 18 22 January 2003 and 4-11 July 2003.

[16] The Maurienne Valley is much longer than Chamonix (about $80 \mathrm{~km}$ long) and is generally wider (about $3-$ $5 \mathrm{~km}$ wide), although there are several points where the valley floor is only a few hundred meters wide. The elevation of the valley floor ranges from $400 \mathrm{~m}$ at the mouth to $2000 \mathrm{~m}$ at the pass at the upper end, and the surrounding mountains are not as high as in Chamonix (the highest is $3852 \mathrm{~m}$ tall). The permanent population is much higher (about 45,000), but most is concentrated in a few small cities at the lower end of the valley. There are also 


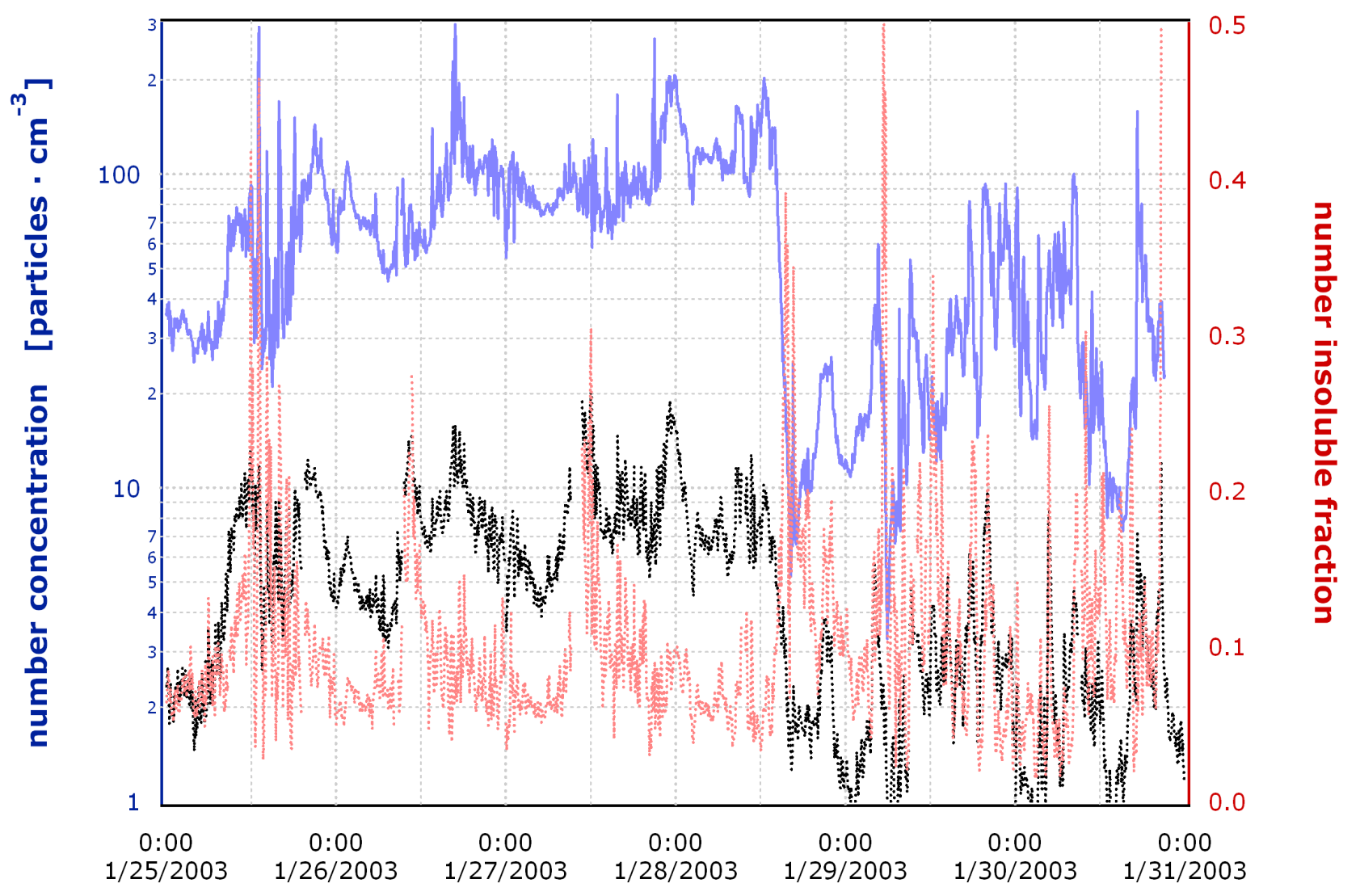

Figure 6. Time series of the total aerosol and WIA number concentration in the Maurienne Valley during the winter 2003 campaign. Displayed data show the sum of all particles in the size range 0.3$2.0 \mu \mathrm{m}$. Total aerosol, solid blue line; WIA, dotted black line; number insoluble fraction, dotted red line.

several industrial sites in the lower part of the valley including plants for steel and aluminum production. As in Chamonix, this valley contains both a major highway which utilizes a tunnel to cross the Alps into Italy (the Fréjus tunnel in this case) and a smaller roadway which winds over the pass at the top end of the valley. The intensive sample site in the Maurienne Valley was located at an unoccupied public camping ground in the small town of Orelle. This site is $20 \mathrm{~km}$ up the valley from St. Jean de Maurienne (the major population and industrial center of the valley) and $13 \mathrm{~km}$ down the valley from Modane (where the entrance to the Fréjus tunnel is located). The valley floor is only a few hundred meters wide in Orelle, so the highway at this point is constructed through a tunnel in the side of the mountain for a distance of a few kilometers. Although vehicle traffic is underground as it passes the sample site, a ventilation outlet for this tunnel is located approximately $500 \mathrm{~m}$ up the valley and $20 \mathrm{~m}$ lower in elevation. The sample site in Orelle was approximately $30 \mathrm{~m}$ above the valley floor, and the sampling period was 24-30 January 2003 and 25 June to 2 July 2003.

[17] The topography of steep alpine valleys such as Chamonix and Maurienne lead to several unique meteorological phenomena. In terms of influence on particle concentration, the two most important of these are related to the diurnal variation of the mixing height and the cycle between up- and down-valley winds [Anquetin et al., 1998]. The diurnal variation in the thickness of the well-mixed boundary layer in alpine valleys is exaggerated when compared to more open terrain. As is typical for many types of topography, ground-level inversion layers tend to develop overnight and then are broken up in the morning as a result of solar heating of the surface. In steep valleys, two special factors serve to make this cycle more pronounced. First, the height of the valley walls prevents penetration of sunlight to the valley floor until later in the morning. This serves to preserve the inversion layer for a longer portion of the day as well as to reduce the ultimate height the mixing layer can achieve before nightfall. This effect is more pronounced during the winter season at middle to high latitudes. Second, the close horizontal spacing of the valley walls confine emissions to a much smaller mixing volume compared to open terrain resulting in much higher concentrations for otherwise identical sources. In addition, the valley walls also act as a profound constraint on wind direction. For this reason, it is more useful to refer to wind direction in terms of up-valley (from low to high elevation) or down-valley rather than cardinal direction. During daylight hours, solar insolation heats the surface-level air parcels and induces them to rise which leads to up-valley air flow. This results in mixing of the valley air with regional-scale air parcels. At night, radiative cooling of surface-level air leads to subsidence and a down-valley air flow. This nighttime wind is 

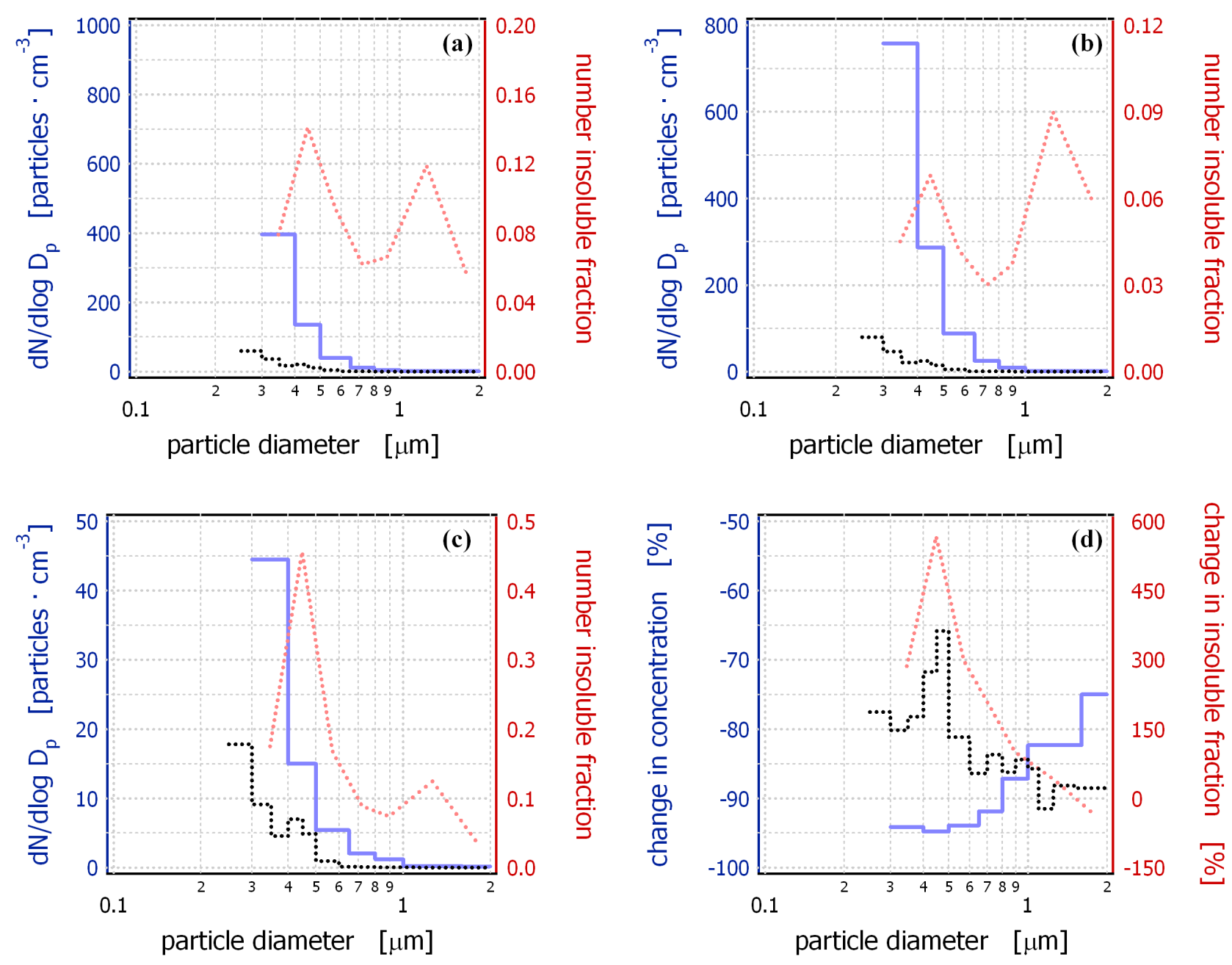

Figure 7. Number size distribution of the total aerosol and WIA number concentration in the Maurienne Valley during the winter 2003 campaign. Figure $7 \mathrm{a}$ is averaged over the entire sampling period, Figure $7 \mathrm{~b}$ shows the 30-min period before the snowfall event of 28 January, and Figure 7c is the 30 min following the commencement of snowfall. Figure 7d shows the percent change in concentration between before and after snowfall. Total aerosol, solid blue line; WIA, dotted black line; number insoluble fraction, dotted red line.

typically weaker than the daytime up-valley wind. This pattern is more pronounced during the summer season when there is more intense surface insolation [Anquetin et al., 1998]. At all times of year, this cycle is influenced by synoptic-scale circulation.

\section{Results and Discussion}

[18] Recognizing that the underlying meteorology has significant differences between winter and summer, the results of the intensive campaigns have been organized to allow more logical analysis of the data. Results are presented first by season and then by location, resulting in four different sets of results. Each set is organized in a similar manner, therefore a detailed explanation is only provided for the first case. For the remaining three cases, only interesting observations or implications are discussed. In addition, a summary of the results from all four portions of this study is presented in Table 1 . The number size distri- butions are presented using the nominal particle diameters reported by the particle counters and have not been altered to account for different particle refractive indices.

\subsection{Winter Results}

\subsubsection{The Chamonix Valley}

[19] Figure 1 shows a time series of the total aerosol and WIA number concentration in the Chamonix Valley during the winter 2003 campaign. These number concentrations are shown on a log scale on the left axis while the fraction (by number) of particles which are water-insoluble is shown on a linear scale on the right axis. The data show the sum of all particles in the size range $0.3-2.0 \mu \mathrm{m}$. Simultaneous measurements of mass concentration using a MOUDI cascade impactor indicate that $75-85 \%$ of the particle mass is within this size range. The number concentration varies by as much as an order of magnitude on timescales as short as a matter of minutes. The number insoluble fraction averaged $11 \%$ over this time period but reached as high 


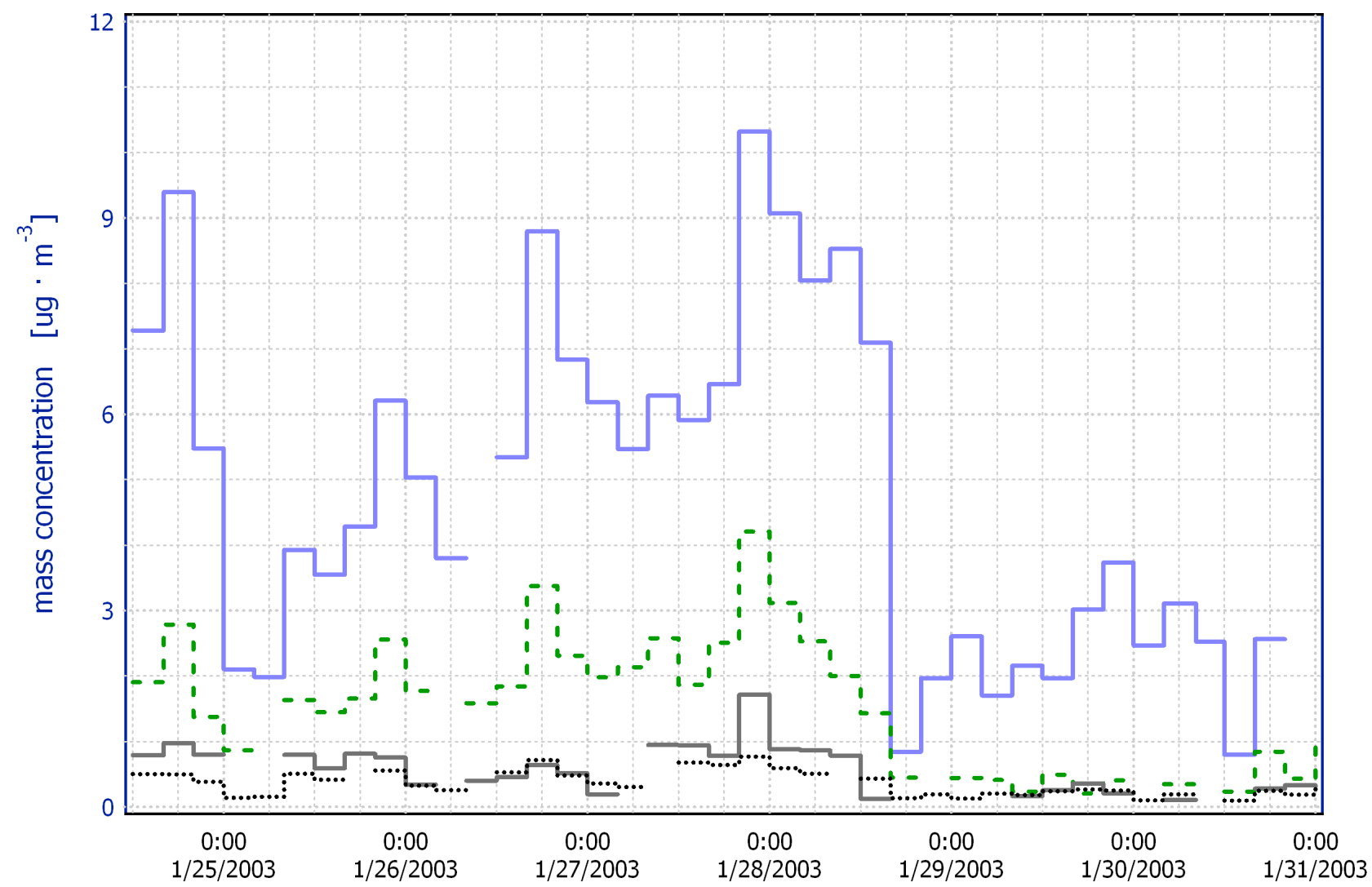

Figure 8. Time series of the elemental and organic carbon mass concentration in the Maurienne Valley during the winter 2003 campaign. The data were obtained from TOT analysis of $\mathrm{PM}_{2.5}$ filters sampled on 4-hour intervals. Estimates of the total aerosol and WIA mass concentration calculated from the measured number concentration in the size range $0.3-2.0 \mu \mathrm{m}$ are also shown. Total aerosol, solid blue line; WIA, dotted black line; OC mass, dashed green line; EC mass, solid gray line.

as $60 \%$ and was occasionally at levels over $30 \%$ for several hours at a time. It may be seen from this graph that the WIA and total aerosol concentrations frequently fluctuate independently.

[20] Figure 2 illustrates the size distribution over several time intervals during the week of sampling. Figure 2a shows the size distribution averaged over the entire week, Figure $2 \mathrm{~b}$ shows the time around midnight on 20 January 2003 when the total particle concentration was elevated for a period of several hours, and Figure $2 \mathrm{c}$ shows the period in the morning of 21 January 2003 when the concentration was quite low for several hours. Note that the scales are different on these charts. These charts show little difference in size distribution with concentration, and all exhibit peaks in the insoluble fraction at 0.45 and $1.1 \mu \mathrm{m}$. The insoluble fraction tends to be higher at all sizes when the total particle concentration is lower.

[21] Figure 3 shows size-resolved mass concentration $\left(\mathrm{dm} / \mathrm{d} \log \mathrm{D}_{\mathrm{p}}\right)$ for five different data sets averaged over the time periods of the MOUDI runs. The first three data sets are the $\mathrm{EC}, \mathrm{OC}$ and $\mathrm{EC}+\mathrm{OC}$ concentrations determined from the Dekati impactor samples, the next data set is the total particle mass measured gravimetrically using the MOUDI impactor filters, and the final set is an estimate of the WIA mass concentration derived from the average number concentrations over the same time period. Figure $3 \mathrm{a}$ shows $\mathrm{dm} / \mathrm{d} \log$ Dp for the MOUDI run of 18-20 January 2003 , and Figure $3 \mathrm{~b}$ is the run of 20-22 January 2003. The concentration of noncarbonaceous mass (sulfate, nitrate, metals, etc.) is not shown. Therefore it is expected that the MOUDI total mass should exceed EC + OC mass at all sizes. This is generally true except for a few intermittent impactor stages. This discrepancy may be the result of differences in the time of operation of the impactors or of postsampling handling. Since EC is insoluble in water, it was expected that the mass estimated by the LiQuilaz would be equal to or greater than the measured EC mass at all sizes; however, the opposite is more often observed. This is likely due to a combination of the sizing errors explained in the previous section, namely that the impactor tends to oversize EC relative to the LiQuilaz (depending on the mixing state of atmospheric aerosols) and that the LiQuilaz likely undersizes particles due to a difference between the refractive index of the ambient particles and the calibration standard. The latter of these errors is compounded by the fact that WIA mass is an estimated value calculated as a function of particle diameter cubed. Even a slight increase in the size of particles measured by the LiQuilaz would result in much larger WIA mass. In addition, for the purposes of estimating insoluble mass, particles were assumed to be spherical, even though soot particles are known to be fractal agglomerates. The mass estimated by this 


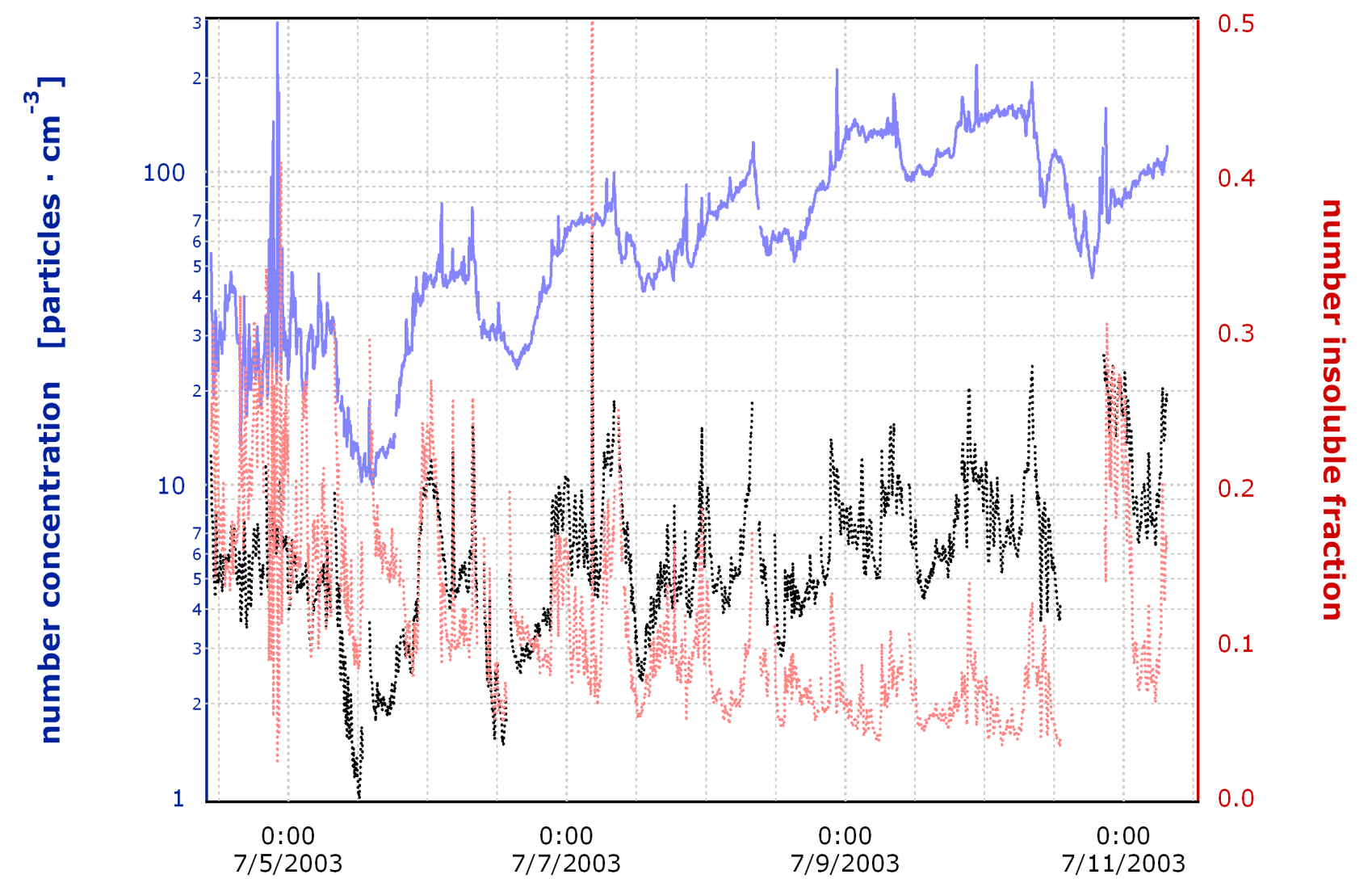

Figure 9. Time series of the total aerosol and WIA number concentration in the Chamonix Valley during the summer 2003 campaign. Displayed data show the sum of all particles in the size range $0.3-2.0 \mu \mathrm{m}$. Total aerosol, solid blue line; WIA, dotted black line; number insoluble fraction, dotted red line.

procedure may conceivably be greater or less than actual insoluble mass. Since these mass calculations are subject to an unquantified uncertainty, these estimates should be interpreted qualitatively. Therefore the most important observation which can be made from the comparison of the WIA calculated mass to the mass measured by the filter samples is that the structure of the particle size distributions are consistent with one another, with peaks between 0.4 and $0.6 \mu \mathrm{m}$.

[22] Figure 4 shows a time series of the $\mathrm{PM}_{2.5} \mathrm{EC}$ and $\mathrm{OC}$ mass in the Chamonix Valley measured using TOT analysis of the 4-hour filters. For comparison, estimates of the total and WIA mass averaged over the same time periods are also shown. These mass estimates were calculated from the realtime number concentrations as described in the previous section. The filters collect particles of all sizes smaller than $2.5 \mu \mathrm{m}$, whereas the real-time instrument only measures the size range of $0.25-2.0 \mu \mathrm{m}$. Examination of the impactor data reveals that in winter, $18 \%$ of the $\mathrm{PM}_{2.5} \mathrm{EC}$ mass and $15 \%$ of the $\mathrm{PM}_{2.5}$ OC mass is smaller than $0.2 \mu \mathrm{m}$ while in summer, $25 \%$ of the $\mathrm{PM}_{2.5}$ EC mass and $32 \%$ of the $\mathrm{PM}_{2.5}$ OC mass is smaller than $0.2 \mu \mathrm{m}$. Since the size ranges measured by these two methods do not perfectly correspond to one another, the data are expected to contain noticeable discrepancies even in the absence of other uncertainty. However, a comparison is still useful in that it allows observation of the relative changes in EC and WIA concentration. The structure of each of these time series is for the most part parallel. EC mass consistently exceeds WIA mass by a factor of approximately three. This is likely due to the size range issues described above as well as the uncertainty in the sizing of soot particles by the LiQuilaz which is compounded during the conversion from number to mass concentration.

[23] Figure 5 shows EC and OC 4-hour average mass plotted against the estimated mass of WIA averaged over the same time periods. Linear regressions are shown as solid lines. Figure 5a shows the winter results from the Chamonix Valley. The WIA mass is more closely correlated with EC mass than with OC mass. Given that EC is completely water-insoluble, the slope of the WIA-EC regression should theoretically be less than or equal to unity. The fact that it is significantly greater than one during three of the four campaigns is most likely a result of uncertainty in calculating WIA mass from the number concentration and the difference in size ranges measured by the two methods. The slope of the WIA-EC regression is approximately three times higher in the Chamonix Valley during the winter campaign than in any of the other campaign phases. By comparing the EC size distributions of Figure 3 to those for the other sites, it may be seen that the EC size distribution in the Chamonix Valley during the winter campaign was slightly shifted toward larger sizes relative to other sites. As previously mentioned, EC particles larger than $0.8 \mu \mathrm{m}$ are undersized by the LiQuilaz SO2, and this uncertainty in sizing may have led to an underestimation of WIA mass and 

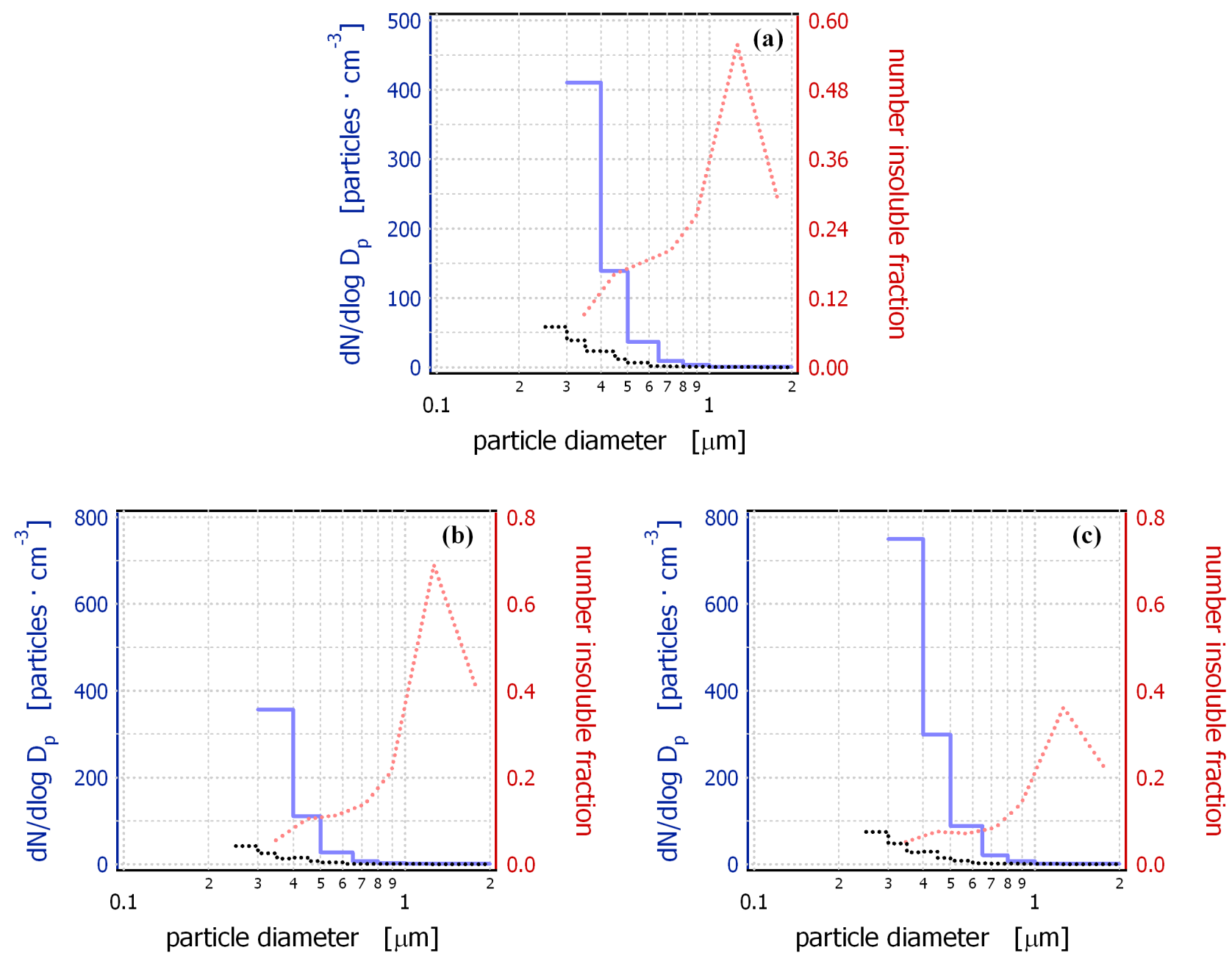

Figure 10. Number size distribution of the total aerosol and WIA number concentration in the Chamonix Valley during the summer 2003 campaign. Figure 10a is averaged over the entire sampling period, Figure 10b shows a typical daytime period ( $8 \mathrm{July}$ ), and Figure 10c shows a typical nighttime period (8-9 July). Total aerosol, solid blue line; WIA, dotted black line; number insoluble fraction, dotted red line.

consequently a higher WIA-EC regression slope. This site was more significantly influenced by smoke from woodburning stoves than other sites, and it may be possible that this difference in EC sources may have led to the observed differences in the size distributions [Marchand, 2003].

\subsubsection{The Maurienne Valley}

[24] A time series of the number concentration in the Maurienne Valley during the winter campaign is shown in Figure 6. The concentration was generally about a factor of two lower in Maurienne than in Chamonix and again varied dramatically on short timescales. The number insoluble fraction averaged $9.5 \%$ over the entire sample period. A heavy snowfall event began on the afternoon of 28 January and continued into the following day. Following the onset of snowfall, the total particle concentration quickly dropped by an order of magnitude. The WIA concentration on the other hand did not diminish to a similar degree and the insoluble fraction consequently increased by a factor of eight (from $5 \%$ to $40 \%$ ) over the course of two hours. Figure 7 shows the number size distributions for the
Maurienne Valley. Figure 7a shows the average size distribution for the entire week, but more interestingly, Figures $7 \mathrm{~b}$ and $7 \mathrm{c}$ show the size distribution for the thirty minute periods preceding and following the commencement of the snowfall event. The insoluble fraction increased for all but the largest particles following the snow, but this increase was much more pronounced at $0.45 \mu \mathrm{m}$ (increase from $6.8 \%$ to $45.6 \%$ in a matter of minutes). An air mass change was associated with this snowfall event and the wind direction shifted from up- to down-valley. Figure $7 d$ shows as a function of size the percent change in number concentration (left axis) and insoluble fraction (right axis) between the $30 \mathrm{~min}$ before the snow began and the $30 \mathrm{~min}$ after. This graph shows that the change in concentration is negative for all particles, but more negative for the smallest ones. This is contrary to what would be expected for precipitation scavenging given that the principal physical mechanisms for the removal of particles by precipitation are impaction and diffusion, which preferentially remove particles larger than $1.0 \mu \mathrm{m}$ and smaller than $0.1 \mu \mathrm{m}$ respectively [Greenfield, 

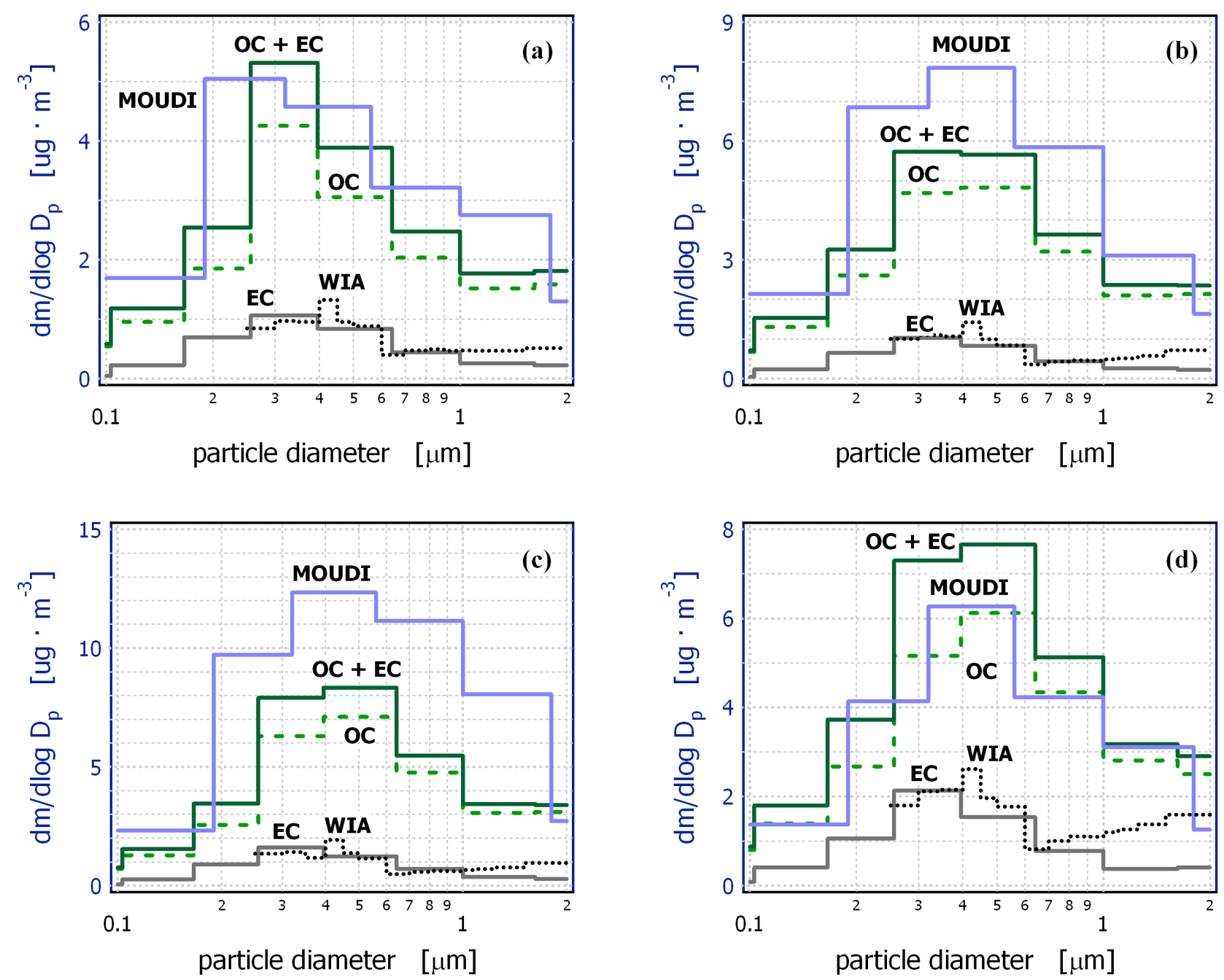

Figure 11. Mass size distributions in the Chamonix Valley during the summer 2003 campaign. Figure $11 \mathrm{a}$ is for the time period of $4-6$ July, Figure $11 \mathrm{~b}$ is for $6-8 \mathrm{July}$, Figure $11 \mathrm{c}$ is for $8-10 \mathrm{July}$, and Figure $11 \mathrm{~d}$ is for 10-11 July 2003.

1957]. In other words, the change in concentration was expected to be least negative for particles $0.1-1.0 \mu \mathrm{m}$, whereas the opposite is observed. This implies that precipitation scavenging is probably not responsible for the change in particle size distributions, but rather that the particle populations being sampled were different before and after the onset of the snowfall event. For insoluble particles, the structure of this graph is more complex and difficult to interpret. The concentration of insoluble particles larger than $0.5 \mu \mathrm{m}$ is diminished by roughly $80-90 \%$ from what it had been before the snowfall, but for particles between 0.4 and $0.5 \mu \mathrm{m}$, the concentration is reduced by just over half. This results in the number insoluble fraction at this size to be extremely high during the period following the onset of snow, reaching as high as $40 \%$. This unusual structure gradually diminishes over a period beginning approximately $30 \mathrm{~min}$ after the snowfall began until six hours later, at which time the structure of the size distribution once again closely resembled the average for the week. Snowfall was heavy throughout this time period.
[25] Figure 8 shows a time series of EC and OC 4-hour average mass as well as estimates of total aerosol and WIA mass. As in Chamonix, the structure of these curves closely match one another. Figure $5 \mathrm{~b}$ shows EC and OC mass plotted against the estimated mass of WIA for the Maurienne Valley in winter. This graph shows a close correlation of EC and WIA mass, although unlike in Chamonix, the correlation of OC and WIA is higher than that of EC and WIA mass. This high correlation could conceivably be the result of either the presence of insoluble organic aerosols or simply the fact that OC mass is highly correlated with EC mass.

\subsection{Summer Results}

\subsubsection{The Chamonix Valley}

[26] Figure 9 shows a time series of the total aerosol and WIA number concentrations in the Chamonix Valley during the summer campaign. The concentration in the summer averaged about a factor of two lower than during the winter campaign, most likely due to the fact that the afternoon mixing height is typically much higher in the summer and 


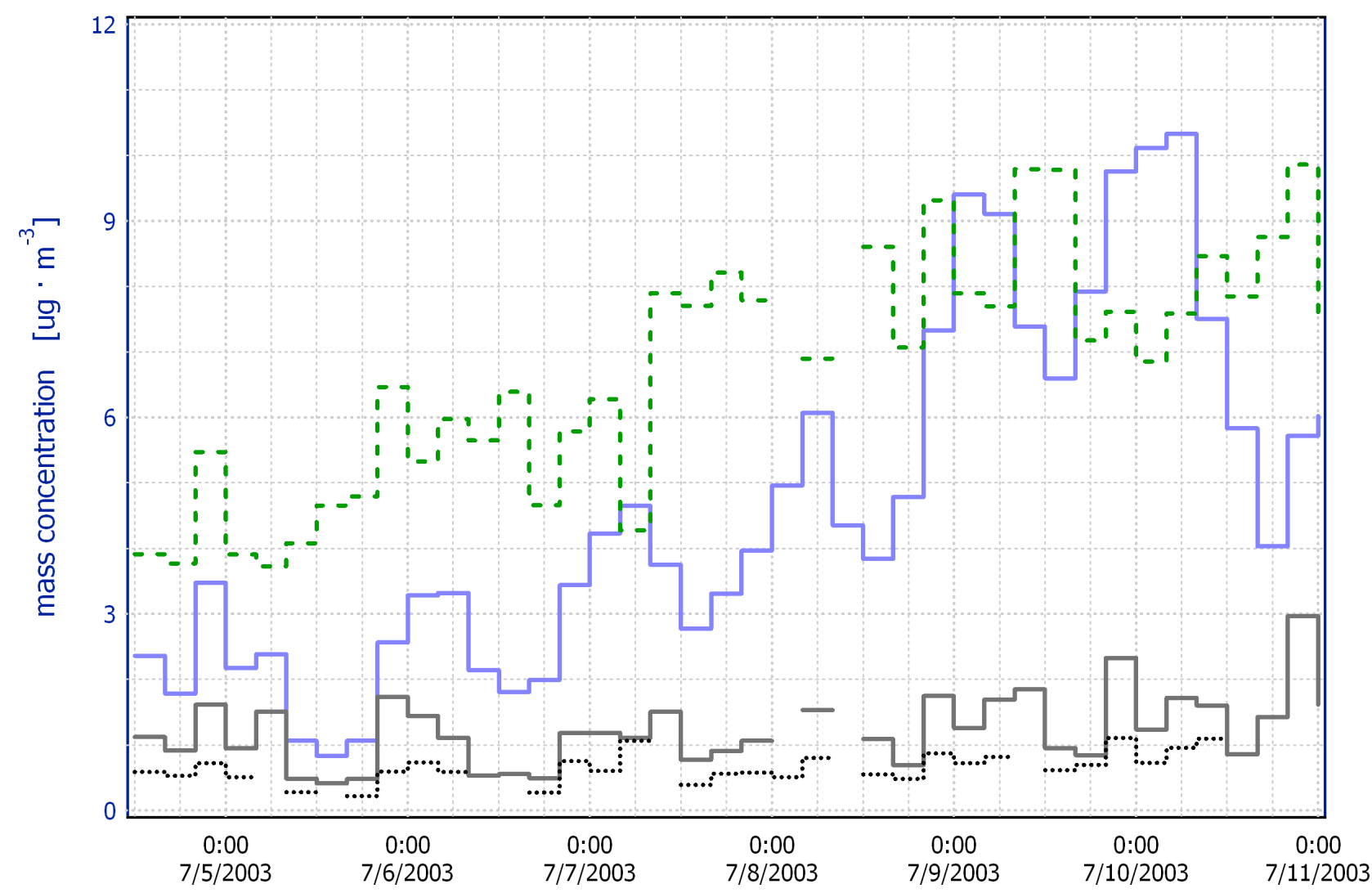

Figure 12. Time series of the elemental and organic carbon mass concentration in the Chamonix Valley during the summer 2003 campaign. The data were obtained from TOT analysis of $\mathrm{PM}_{2.5}$ filters sampled on 4-hour intervals. Estimates of the total aerosol and WIA mass concentration calculated from the measured number concentration in the size range $0.3-2.0 \mu \mathrm{m}$ are also shown. Total aerosol, solid blue line; WIA, dotted black line; OC mass, dashed green line; EC mass, solid gray line.

that there was less biomass burning for residential heating. The average insoluble fraction was $11.2 \%$, essentially the same as was observed in January. The first day of the Chamonix summer campaign was cool with steady rainfall. The rest of the campaign was characterized by exceptionally hot and sunny stagnant conditions. Following the initial rainfall, the atmosphere was relatively clean, and the total particle concentration steadily increased throughout the week as a result of stagnant meteorological conditions favoring secondary organic aerosol formation. Unlike during the winter campaign, there was a clear diurnal pattern in particle number concentration, with higher concentrations being observed at night and during the early morning hours when the mixing height is at a minimum. Contrary to the total particle concentration, the WIA concentration did not display an upward or downward trend throughout the week. Thus there was a clear downward trend in the insoluble fraction as the week progressed. This can be explained by noting that during summertime mornings, as the mixing height increases, well-mixed air from outside the valley is introduced by the up-valley wind. Each day, this outsidethe-valley background concentration increased due to continental-scale meteorology resulting in higher total number concentrations. The WIA concentration on the other hand is more a function of vehicular sources within the valley. These sources remained generally the same throughout the week, resulting in little change in WIA concentration aside from the diurnal variation.

[27] Figure 10 shows a series of size distributions averaged over several time periods during the Chamonix summer campaign. Figure 10a shows the average time period for the entire week. Figure $10 \mathrm{~b}$ shows a typical daytime period ( 8 July), and Figure 10c shows a nighttime period (8-9 July). The structure of these size distributions is similar during each time period, although there is a slightly higher fraction of large insoluble aerosols observed during the day than during the night.

[28] Figure 11 shows the size distributions associated with the time periods of the MOUDI runs. Figure 11a is averaged over the time period 4-6 July, Figure $11 \mathrm{~b}$ is averaged over $6-8$ July, Figure $11 \mathrm{c}$ is averaged over 8 10 July, and Figure 11d is averaged over 10-11 July. These charts show excellent agreement between the different measurement methods. The total MOUDI mass is equal to or exceeds $\mathrm{EC}+\mathrm{OC}$ at most sizes for all four runs as expected. In addition, the estimated WIA mass equals or exceeds the EC mass at all sizes on all runs; however, since there is significant uncertainty associated with estimating WIA mass from number concentration, this does not necessarily suggest that WIA is entirely composed of EC. A substantial portion of WIA mass could conceivably be composed of OC or crustal elements. During all four 


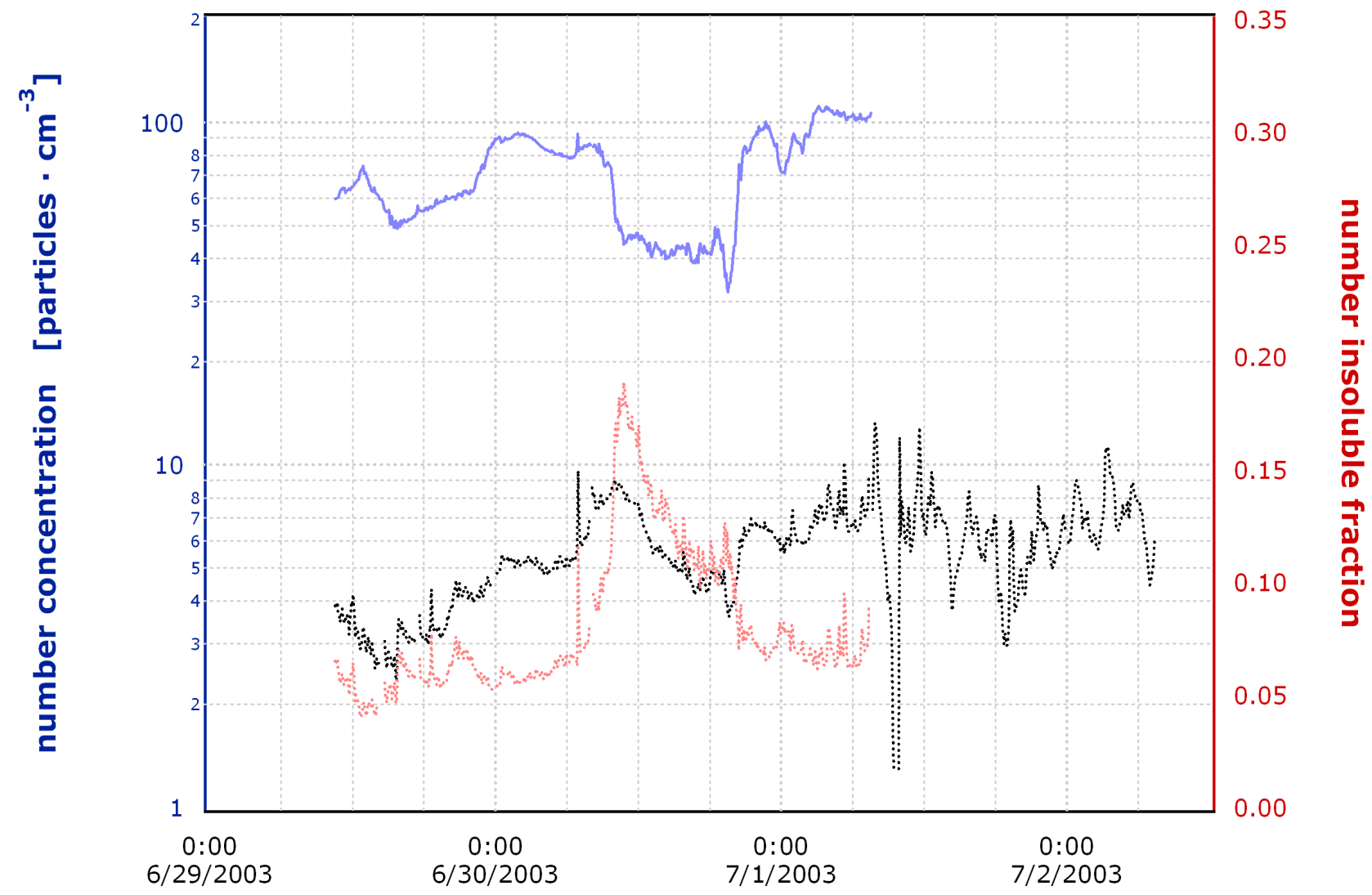

Figure 13. Time series of the total aerosol and WIA number concentration in the Maurienne Valley during the summer 2003 campaign. Displayed data show the sum of all particles in the size range $0.3-2.0 \mu \mathrm{m}$. Total aerosol, solid blue line; WIA, dotted black line; number insoluble fraction, dotted red line.

periods, there is a slight trend toward increasing WIA mass at sizes larger than $1.0 \mu \mathrm{m}$. This same trend is not observed in either the EC or OC mass size distributions, suggesting wind-blown dust as a possible source of these particles. As particle concentrations increased throughout the week, the size distributions exhibited a slight shift toward larger diameters.

[29] Figure 12 shows a time series of the EC and OC mass measured by the 4-hour filters plotted alongside estimates of the total and WIA mass averaged over the same time periods. Although EC mass exceeds the estimate of WIA mass at all time intervals, the two values fluctuate concurrently. This may not be said of WIA estimated mass and OC mass. OC mass is frequently observed to increase while WIA mass decreases and vice versa. Figure $5 \mathrm{c}$ shows a regression of EC and OC mass measured by the 4-hour filter samples with estimated WIA mass averaged over the same time period. WIA mass is highly correlated with EC, but essentially uncorrelated with OC. The slope of the ECWIA regression is again greater than one for the same reasons discussed above.

\subsubsection{The Maurienne Valley}

[30] Owing to transportation and shipping delays, the WIA instrumentation was only able to run for the final three days of the summer campaign in the Maurienne Valley. The total aerosol particle counter was taken off-line for transport to Chamonix a day in advance of the WIA instrumentation, resulting in just two days of concurrent measurements. A time series of the number concentration observations is shown in Figure 13. The total concentration in Maurienne was about a third lower than in Chamonix. The insoluble fraction over this time period ranged from 5

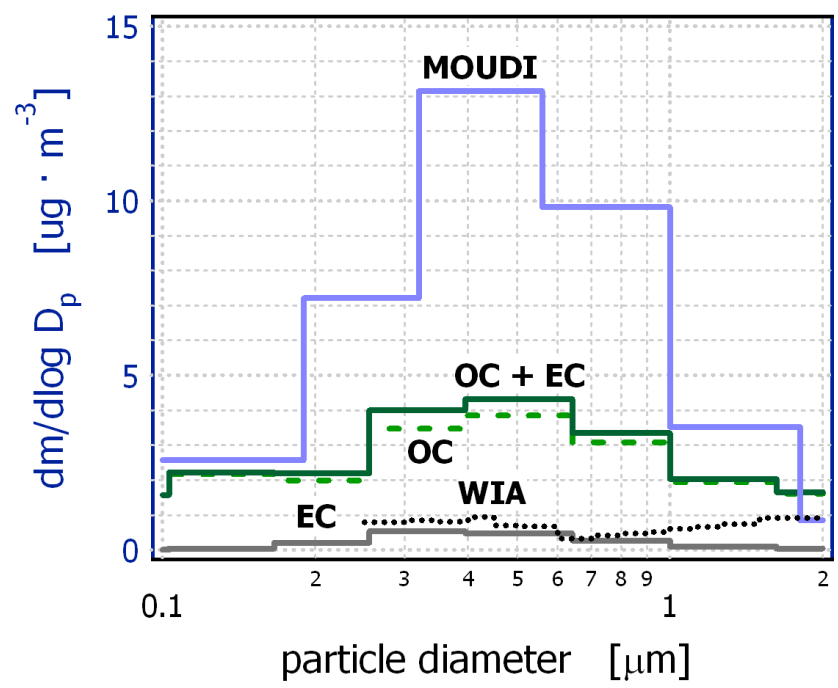

Figure 14. Mass size distributions in the Maurienne Valley during the summer 2003 campaign. The time period for these impactor samples was 29-30 June 2003. 


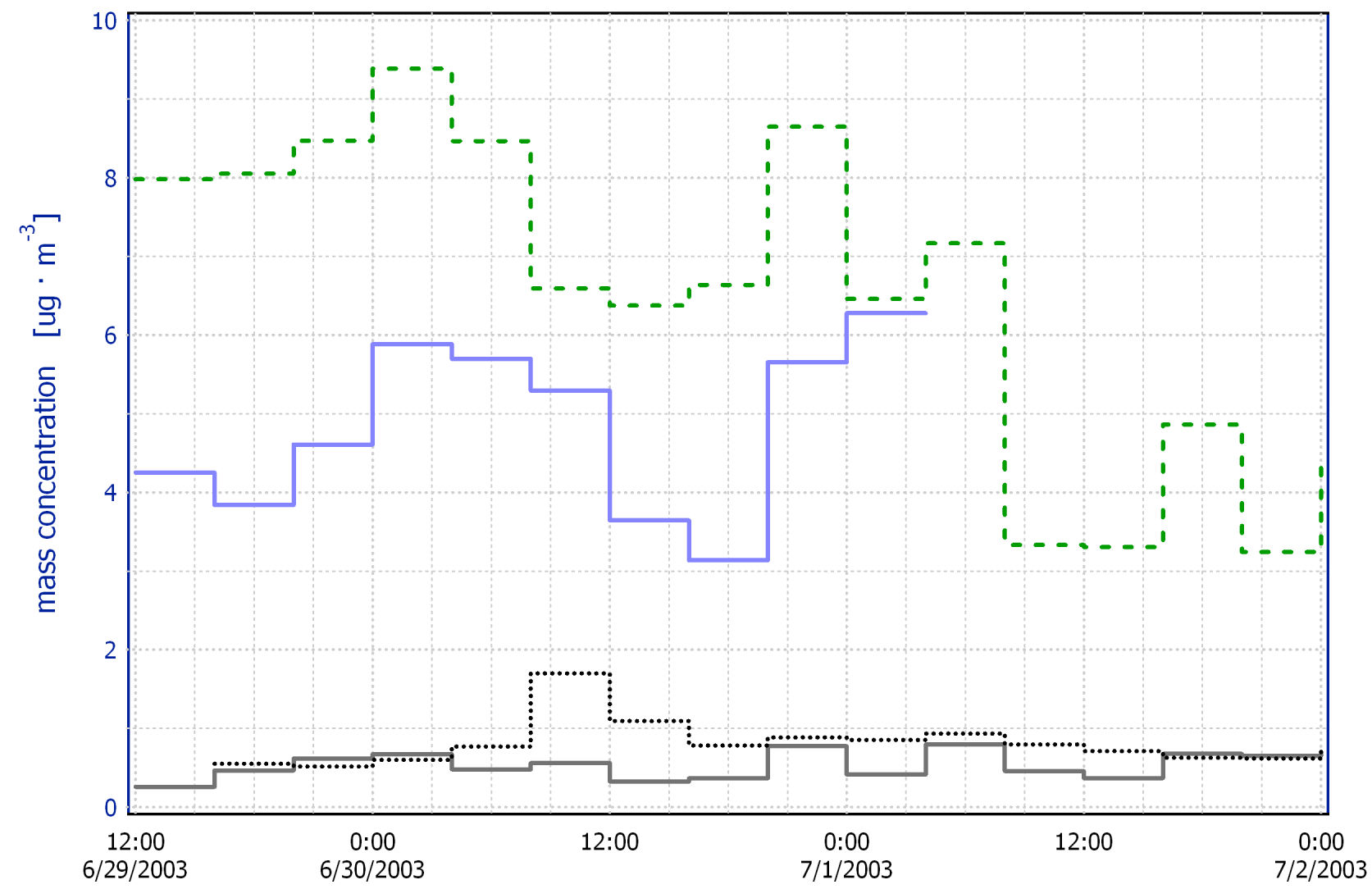

Figure 15. Time series of the elemental and organic carbon mass concentration in the Maurienne Valley during the summer 2003 campaign. The data were obtained from TOT analysis of $\mathrm{PM}_{2.5}$ filters sampled on 4-hour intervals. Estimates of the total aerosol and WIA mass concentration calculated from the measured number concentration in the size range $0.3-2.0 \mu \mathrm{m}$ are also shown. Total aerosol, solid blue line; WIA, dotted black line; OC mass, dashed green line; EC mass, solid gray line.

to $19 \%$ with an average of $8.2 \%$. Although only one complete diurnal cycle is observed, the pattern is consistent with that observed in the Chamonix Valley: the total particle concentration is highest at night when the mixing height is lowest and decreases during the day as the mixing height is elevated and outside air is advected into the valley.

[31] Figure 14 shows a size distribution obtained during a MOUDI run. The total particle mass exceeds the sum of EC
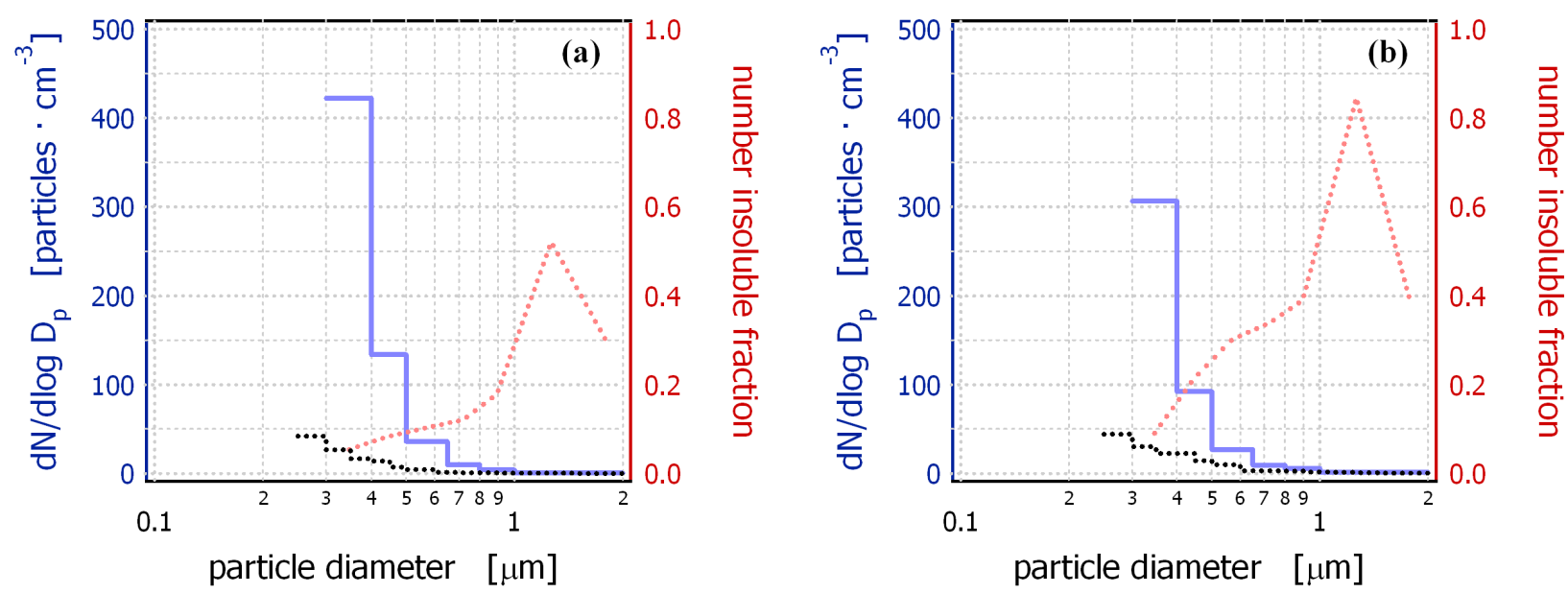

Figure 16. Number size distribution of the total aerosol and WIA number concentration in the Maurienne Valley during the summer 2003 campaign. Figure 16a is for the night of 29-30 June, when WIA and EC concentrations tracked together, and Figure $16 \mathrm{~b}$ is for the daylight period of 30 June, when the two concentrations diverged. Total aerosol, solid blue line; WIA, dotted black line; number insoluble fraction, dotted red line. 
and OC mass for all particles smaller than $2.0 \mu \mathrm{m}$. There is a peak in both the total and the OC mass between 0.3 and $0.6 \mu \mathrm{m}$. EC mass has a very broad peak between 0.25 and $1.0 \mu \mathrm{m}$. Estimated WIA mass exceeds EC mass at all sizes. Figure 15 shows a time series of the 4-hour averages of EC and OC mass. Estimated WIA mass is equal to or greater than EC mass at all times. Beginning in the early morning of 30 June, the estimated WIA mass seems to be decoupled from EC or OC concentration. The magnitude of this decoupling reaches a maximum on the afternoon of 30 June, though the WIA concentration continues to fluctuate independently of EC mass for the remainder of the sampling period. Figure 16 shows the number size distributions averaged over eight hour periods both during and before this occurred. It may be seen from these charts that the size distribution of both the total aerosol population and WIA shifted toward larger sizes during this time period. Possible explanations for these larger insoluble particles include pollen and dust. The OC concentration of the same size particles actually decreases at this time, but this does not necessarily exclude pollen as a possibility since other sources of OC could have decreased by an even greater amount. Another possibility is wind-blown dust. Examination of the total aerosol concentration measured by the GRIMM dust monitor reveals that the percentage of particles larger than $2.0 \mu \mathrm{m}$ increased by a factor of four during this time period (from $0.03 \%$ to $0.12 \%$ ). Particles of that diameter are too large to be sized by the LiQuilaz, so it is not known whether or not they are insoluble, but an increase in the concentration of extremely large particles is consistent with an influx of wind-blown dust.

[32] Figure 5d shows a regression of EC and OC mass against estimated WIA mass. There are far fewer data points for this campaign than for the three others. In addition, as discussed in the previous paragraph, the time series of WIA concentration shows evidence of being influenced by a noncarbonaceous particle source, possibly mineral aerosols. For this reason, the estimated WIA mass shows no correlation with either EC or OC mass.

\section{Conclusions}

[33] A method to measure the size-resolved concentration of water-insoluble aerosol in real time has been developed and successfully implemented in a field study in the Chamonix and Maurienne Valleys of the French Alps. This technique has shown that the concentration of insoluble particles is significant and that it fluctuates on timescales much too brief to be captured by filter samples, as short as a few minutes. In the alpine valleys examined in this study, the fraction (by number) of particles which are waterinsoluble averages around $10 \%$ in both summer and winter. This is a factor of two higher than the insoluble fraction observed during a field test of this instrumentation in a rural area near Atlanta, Georgia in August 2002 even though the total number concentrations at the two sites were comparable [Greenwald et al., 2005]. Examination of the time evolution of particle concentrations shows a pattern of WIA being independently superimposed upon a larger background concentration of all types of aerosol. This pattern is especially pronounced during the summer when the daily evolution of mixing height draws in well-mixed air from outside the valley. Comparison of the time series of WIA concentration with filter-based EC and OC measurements shows closer correlation with elemental carbon than organic carbon. Likewise, comparison of estimated sizeresolved WIA mass concentration derived from optically measured number concentration shows reasonable agreement with size-resolved elemental carbon measurements. Taken together, these observations suggest that elemental carbon emissions within the valleys are dominant sources of insoluble aerosol.

[34] The size-resolved insoluble fraction consistently exhibits a bimodal distribution with peaks observed at 0.45 and $1.1 \mu \mathrm{m}$ during all four campaigns. The WIA number size distribution is also relatively consistent with only a few transient exceptions being observed. During the winter phase of sampling in the Maurienne Valley, a snowfall event was observed to substantially increase the insoluble peak at $0.45 \mu \mathrm{m}$. It is likely that this increase in insoluble fraction was influenced by an air mass change associated with the advance of a cold front through the valley. During the summer campaign in the Maurienne Valley, there was an extended time period during which the WIA concentration increased significantly with no corresponding increase in elemental carbon. At this time, the size distribution of the insoluble fraction was observed to shift to larger sizes. Simultaneously, the fraction of particles larger than $2.0 \mu \mathrm{m}$ increased by a factor of four. Although it is not known if these large particles were insoluble, these observations are consistent with an increase in the concentration of wind-blown dust.

[35] This field implementation of the WIA measurement technique has demonstrated the utility of this system and suggested the importance of its continued use. The results of this study imply that the dominant source of WIA in the regions examined is anthropogenic soot from motor vehicle emissions. An important secondary source is mineral dust. Furthermore, by examining the location of the peak of the WIA size distribution, it is possible to distinguish between the two. Given the significance of the climatic and health implications of soot and mineral dust, the information gleaned from this and similar future studies is of relevance to climate modelers and policy makers and merits pursuance.

[36] Acknowledgment. We gratefully acknowledge the NSF Atmospheric Chemistry Program (proposal 0118579) for funding the development of the water-insoluble aerosol measurement technique and the Laboratoire de Glaciologie et Géophysique de l'Environnement for assisting our participation in the PoVA program.

\section{References}

Anquetin, S., C. Guilbaud, and J.-P. Chollet (1998), The formation and destruction of inversion layers within a deep valley, J. Appl. Meteorol., $37,1547-1560$.

Birch, M. E., and R. A. Cary (1996), Elemental carbon-based method for monitoring occupational exposures to particulate diesel exhaust, Aerosol Sci. Technol., 25, 221-241.

Brook, R. D., J. R. Brook, B. Urch, R. Vincent, S. Rajagopalan, and F. Silverman (2002), Inhalation of fine particulate air pollution and ozone causes acute arterial vasoconstriction in healthy adults, Circulation, 105, $1534-1536$

Ebert, M., S. Weinbruch, P. Hoffmann, and H. M. Ortner (2004), The chemical composition and complex refractive index of rural and urban influenced aerosols determined by individual particle analysis, Atmos. Environ., 38, 6531-6545. 
Greenfield, S. (1957), Rain scavenging of radioactive particulate matter from the atmosphere, J. Meteorol., 14, 115-125.

Greenwald, R., M. H. Bergin, C. M. Carrico, and D. Grant (2005), A new real-time technique to measure the size-distribution of water-insoluble aerosols, Environ. Sci. Technol., 39, 4967-4973.

Hanel, G. (1976), The properties of atmospheric aerosol particles as functions of the relative humidity at thermodynamic equilibrium with the surrounding moist air, Adv. Geophys., 19, 73-188.

Hess, W. M., and C. R. Herd (1993), Microstructure, morphology and general physical characteristics, in Carbon Black: Science and Technology, edited by J.-B. Donnet, R. C. Bansal, and M.-J. Wang, pp. 89-173, Marcel Dekker, New York.

Hull, P., I. Shepherd, and A. Hunt (2004), Modeling light scattering from diesel soot particles, Appl. Opt., 43, 3433-3441.

Jaffrezo, J. L., G. Aymoz, and J. Cozic (2005a), Size distribution of EC and $\mathrm{OC}$ in the aerosol of Alpine valleys during summer and winter, Atmos. Chem. Phys. Discuss., 5, 3773-3809.

Jaffrezo, J.-L., G. Aymoz, C. Delaval, and J. Cozic (2005b), Seasonal variations of the water soluble organic carbon mass fraction of aerosol in two valleys of the French Alps, Atmos. Chem. Phys. Discuss., 5, 3999-4036.

Janzen, J. (1980), Extinction of light by highly nonspherical strongly absorbing colloidal particles: Spectrophotometric determination of volume distributions for carbon blacks, Appl. Opt., 19, 2977-2985.

Laakonsen, A., P. Korhonen, M. Kulmala, and R. J. Charlson (1998), Modification of the Köhler equation to include soluble trace gases and slightly soluble substances, J. Atmos. Sci., 55, 853-862.

Le Tertre, A., et al. (2002), Short-term effects of particulate air pollution on cardiovascular diseases in eight European cities, J. Epidemiol. Commun. H., 56, 773-779.

Lide, D. R. (2004), Handbook of Chemistry and Physics, CRC Press, Boca Raton, Fla.

Marchand, N. (2003), Etude de la composante organique de l'aérosol atmosphérique: Cas de deux vallées alpines (Chamonix et Maurienne), et développement analytique, Ph.D. thesis, 262 pp., Université de Savoie, Chambéry, France.

Metzger, K. B., P. E. Tolbert, M. Klein, J. L. Peel, W. D. Flanders, K. Todd, J. A. Mulholland, P. B. Ryan, and H. Frumkin (2004), Ambient air pollution and cardiovascular emergency department visits, Epidemiology, $15,46-56$.

Peel, J. L., P. E. Tolbert, M. Klein, K. B. Metzger, W. D. Flanders, K. Todd, J. A. Mulholland, P. B. Ryan, and H. Frumkin (2005), Ambient air pollution and respiratory emergency department visits, Epidemiology, $16,164-174$

Peters, A., D. W. Dockery, J. E. Muller, and M. A. Mittleman (2001), Increased particulate air pollution and the triggering of myocardial infarction, Circulation, 103, 2810-2815.

Pósfai, M., J. R. Anderson, P. R. Buseck, and H. Sievering (1999), Soot and sulfate aerosol particles in the remote marine troposphere, J. Geophys. Res., 104, 21,685-21,693.

Quenzel, H. (1969), Influence of refractive index on the accuracy of size determination of aerosol particles with light-scattering aerosol counters, Appl. Opt., 8, 165-170.

Saxena, P., L. M. Hildemann, P. H. McMurry, and J. H. Seinfeld (1995), Organics alter hygroscopic behavior of atmospheric particles, J. Geophys. Res., 100, 18,755-18,770.

Sokolik, I. N., and O. B. Toon (1999), Incorporation of mineralogical composition into models of the radiative properties of mineral aerosol from UV to IR wavelengths, J. Geophys. Res., 104, 9423-9444.

Sosnowski, T. R., L. Gradon, and A. Podgórski (2000), Influence of insoluble aerosol deposits on the surface activity of the pulmonary surfactant: A possible mechanism of alveolar clearance retardation?, Aerosol Sci. Technol., 32, 52-60.

Turpin, B. J., P. Saxena, and E. Andrews (2000), Measuring and simulating particulate organics in the atmosphere: Problems and prospects, Atmos. Environ., 34, 2983-3013.

Whitby, K. T., and R. A. Vomela (1967), Response of single particle optical counters to nonideal particles, Environ. Sci. Technol., 1, 801-814.

Yang, H. Z., and J. Z. Yu (2002), Uncertainties in charring correction in the analysis of elemental and organic carbon in atmospheric particles by thermal/optical methods, Environ. Sci. Technol., 36, 5199-5204.

G. Aymoz and J.-L. Jaffrezo, Laboratoire de Glaciologie et Géophysique de l'Environnement (LGGE), Université de Joseph Fourier, F-38402 Saint Martin d'Hères Cedex, France.

M. H. Bergin, School of Civil and Environmental Engineering, School of Earth and Atmospheric Sciences, Georgia Institute of Technology, 311 Ferst Drive, Atlanta, GA 30332, USA.

J.-L. Besombes, Laboratoire de Chimie Moléculaire et Environnement (LCME), Université de Savoie, F-73376 Le Bourget du Lac, France.

R. Greenwald, Department of Pediatrics, Emory University School of Medicine, 2015 Uppergate Drive, Atlanta, GA 30322, USA. (roby_greenwald@oz.ped.emory.edu) 